\title{
Planar Cell Movements and Axial Patterning During Early Gastrulation of the Rabbit Embryo
}

\author{
Dissertation \\ for the award of the degree \\ "Doctor rerum naturalium" (Dr.rer.nat.) \\ of the Georg-August University of Göttingen \\ within the doctoral program Biology \\ of the Georg-August University School of Science (GAUSS)
}

\author{
submitted by \\ Viktoria Stankova \\ (née Halacheva) \\ from Pazardzhik, Bulgaria
}

Göttingen, 2013 
Thesis Committee

Prof. Dr. E. A. Wimmer, Dept. of Developmental Biology GZMB, Georg-August-University Göttingen

Prof. Dr. T. Pieler, Dept. of Developmental Biochemistry, Göttingen University Medical School Prof. Dr. C. Viebahn, Dept. of Anatomy and Embryology, Göttingen University Medical School

Members of the Examination Board

Reviewer: Prof. Dr. E. A. Wimmer

Second Reviewer: Prof. Dr. T. Pieler

Further members of the Examination Board

Prof. Dr. S. Hoyer-Fender, Dept. of Developmental Biology GZMB, Georg-August-University Göttingen

Prof. Dr. J. Großhans, Dept. of Developmental Biochemistry, Göttingen University Medical School

Prof. Dr. A. Stumpner, Dept. of Cellular Neurobiology, Georg-August-University Göttingen

Prof. Dr. A. Mansouri, Molecular Cell Differentiation Group, Max Planck Institute for Biophysical Chemistry

Date of the oral examination: January $21^{\text {st }}, 2014$ 
To my loved ones:

For your support, love and patience. 


\section{Contents}

LIST OF FIGURES ..............................................................................................................................................II

ABBREVIATIONS............................................................................................................................

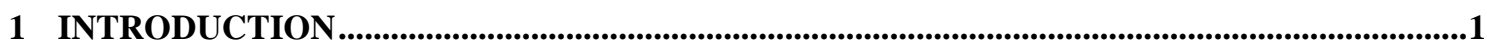

2 METHODS SUMMARY ........................................................................................................................

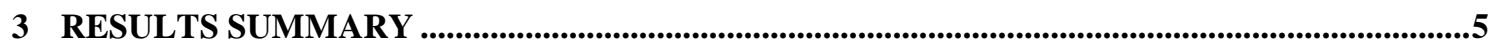

3.1 Planar Cell Movements and Oriented Cell Division …………………………..................

3.2 AXial Patterning Following EXPERIMENTALly Modified Cell Movements.............................5

3.3 UnPublished Data Related to Planar Cell Movements...........................................................6

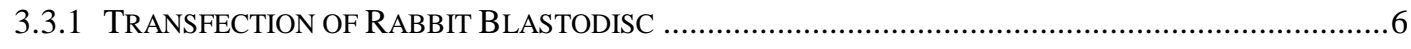

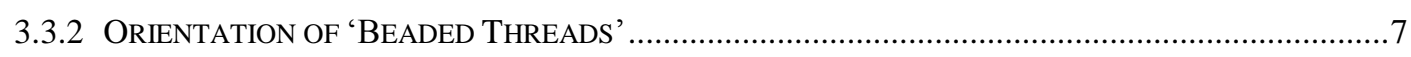

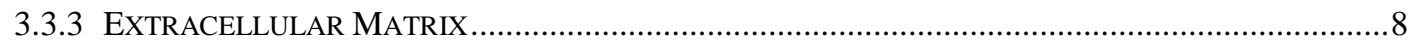

4 DISCUSSION

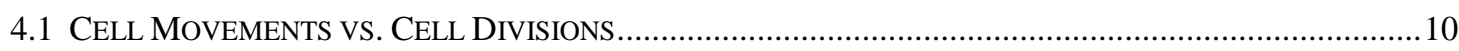

4.2 ROCK-DEPENDENT ACTIN Remodelling Controls Cell Movements........................................11

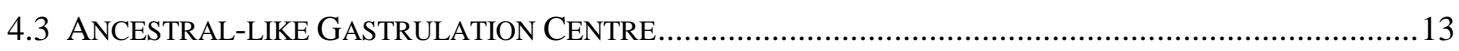

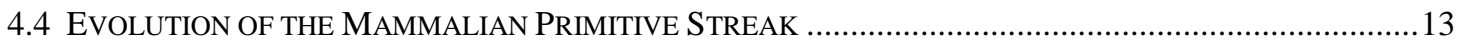

5 CONCLUSION

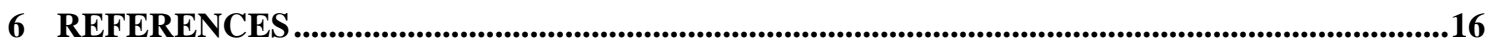

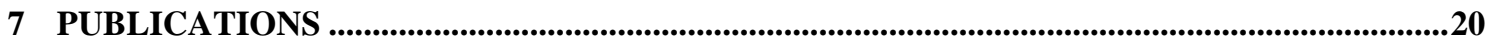

7.1 Published Paper 'Planar Cell Movements and Oriented Cell Division during Early PRIMITIVE STREAK FORMATION IN THE MAMMALIAN EMBRYO' ...................................................2

7.2 Manuscript to Be Submitted 'TRacing AnCeStral Gastrulation through Modified

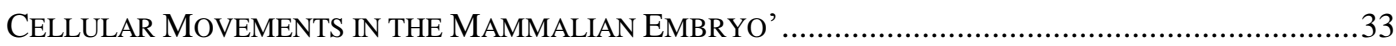

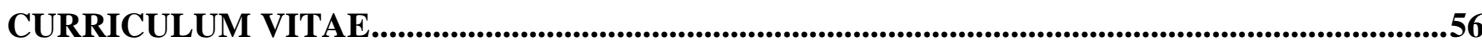

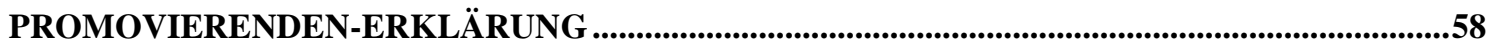

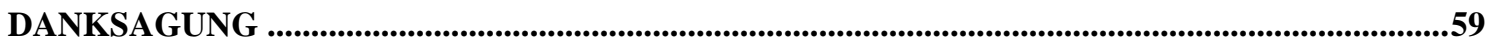




\section{List of Figures}

FIGURE 3-1: ELECTROPORATION OF A RABBIT BLASTOCYST.

FIGURE 3-2: SCANNING ELECTRON MICROSCOPIC ANALYSIS OF ‘BEADED THREADS’ IN A PRE-

GASTRULATING RABBIT EMBRYO

8

FIGURE 3-3: DOUBLE-STAINING OF A WHOLE-MOUNT RABBIT EMBRYONIC DISC FOR HYALURONAN AND

CELL NUCLEI...... 


\section{Abbreviations}

$\begin{array}{ll}\text { A-P } & \text { anterior-posterior } \\ \text { CE } & \text { convergent extension } \\ \text { Cfl1 } & \text { cofilin 1 } \\ \text { DAPI } & 4 \text {,6-diamidino-2-phenylindole } \\ \text { DIC } & \text { differential interference contrast } \\ \text { DiI } & \text { lipophilic carbocyanine dye } \\ \text { DNA } & \text { deoxyribonucleic acid } \\ \text { EGFP } & \text { enhanced green fluorescent protein } \\ \text { EMT } & \text { epithelial-mesenchymal transition } \\ \text { FGF } & \text { fibroblast growth factor } \\ \text { GFP } & \text { green fluorescent protein }\end{array}$

HA hyaluronan (hyaluronic acid)

LatA latrunculin A

$\boldsymbol{\mu g} / \mathbf{m l} \quad$ microgram per millilitre

$\boldsymbol{\mu M}$ micromolar

MLC myosin light-chain

mRNA messenger ribonucleic acid

ms millisecond

PCP planar cell polarity

PGE posterior gastrula extension

PTK7 tyrosine-protein kinase-like 7

ROCK Rho-associated protein kinase

V volt

Vangl2 Van Gogh-like 2 planar cell polarity protein

Wnt Wnt signal transduction pathway 


\section{Introduction}

Gastrulation - famously referred to by Lewis Wolpert as 'the most important time in our life' - is the process in which the embryo becomes three-layered, consisting of ectoderm, endoderm and mesoderm and thereby creates the basis for the 'milieu intérieur' (Bernard, 1859) and the internal organs. In addition, gastrulation is initiated in a specific region and leads to the formation of the first axial structure of the embryo, i.e. the blastopore in amphibian, the embryonic shield in fish and the primitive streak in amniotes (birds and mammals). Thus, the body axes (dorso-ventral, antero-posterior and left-right) of the developing embryo are defined and the newly formed axial structure appears through invagination (blastopore), involution (embryonic shield) or ingression (primitive streak) of prospective mesodermal and endodermal cells from the epiblast layer; the latter process is also known as epithelial-mesenchymal transition (EMT).

Gastrulation requires precise and well-coordinated cellular mechanisms, namely cell movements and cell proliferation which are the fundamental processes for correct shaping of the embryo. Indeed, generally accepted morphogenetic mechanisms needed for vertebrate gastrulation are the complex cell movements which were initially described as 'convergent extension' (CE) movements during the gastrulation in the frog Xenopus laevis (Keller and Danilchik, 1988), in the zebrafish Danio rerio (Warga and Kimmel, 1990) and in the chick Gallus gallus (Lawson and Schoenwolf, 2003). Similar CE movements were also suggested to be important in the mammalian embryo for later stages of gastrulation, e.g. during the primitive streak elongation in the rabbit Oryctolagus cuniculus (Viebahn et al., 2002) or during the neurulation in the mouse Mus musculus (Ybot-Gonzalez et al., 2007). These cellular rearrangements leading to narrowing (convergence) in medio-lateral direction and lengthening (extension) along the anterior-posterior (A-P) axis of the embryo depend on the polarity within the plane of the epithelium or the so-called Wnt-dependent planar cell polarity (Wnt-PCP) pathway, which is known as a conserved mechanism directing cell movements and shaping distinct structures (Seifert and Mlodzik, 2007). The best-studied model among the amniotes regarding cellular and molecular mechanisms of cell movements during gastrulation is the chick embryo. Here, cells near the midline of the posterior domain intercalate in the medio-lateral direction prior to generating the primitive streak as shown in time-lapse movies (Voiculescu et al., 2007); additionally, interruption of the 
Wnt-PCP pathway causes ectopic mesoderm induction found at the periphery of the embryonic disc (Alev et al., 2013; Voiculescu et al., 2007).

In contrast, the role of cell movements in the mammalian gastrulation remains controversial, especially with regard to the cellular mechanisms of primitive streak formation which differ between mammalian models due to the different forms of the embryos (Tam and Behringer, 1997; Viebahn et al., 1995). For example, in the mouse which has an egg cylinder - the primitive streak appears through progressive EMT and thereby minimal cell movements of the epiblast are required (Williams et al., 2012). In addition, during mouse primitive streak formation these minimal cell movements are combined with mesodermal $\mathrm{CE}$ which is controlled by polarized cell behaviour as shown in embryos mutant for PTK7 (Yen et al., 2009) as well as in Vangl2-Cf11 double mutants (Mahaffey et al., 2013). On the other hand, in mammalian species with a flat embryonic disc as is the rabbit, large-scale cell movements lead to extensive cell redistribution from the 'cell-rich' area (lying anterior) to the 'cell-poor' posterior gastrula extension (PGE) area; for example, whirl-like cell movements were proposed on both sides of the midline using the live cell marker DiI (Viebahn et al., 2002). However, in the rabbit embryo molecular factors driving gastrulation still require direct observation and recordings, especially with regard to the dynamic process of streak formation.

In addition to cell movement, cell proliferation is supposed to play an important role prior to gastrulation as well, not only as a mechanism providing the needed cell density in the posterior part of the embryo, but also as a highly regulated process which may support cell movements and thus could contribute to axial elongation as previously shown in zebrafish (Concha and Adams, 1998; Gong et al., 2004) and in the chick embryo (Wei and Mikawa, 2000). However, suggested contribution of cell divisions to primitive streak elongation has not been confirmed in the chick embryo as reported later using specific inhibition of cell division (Chuai et al., 2006; Cui et al., 2005) or through computational analysis (Bodenstein and Stern, 2005). In fact, birds and mammals differ in the topography of the future primitive streak area with respect to cell density, e.g. the 'crowded' Koller's sickle stands in contrast to the 'rarefied' PGE area, respectively; therefore, the data on cell divisions obtained in the chick embryo is not applicable to the mammotypical embryonic disc for which the rabbit can be regarded as a model organism. Following this notion, the question could be asked as to whether cell 
divisions, in addition to cell movements, are critical for primitive streak formation in the mammalian embryo.

Although many aspects of cellular and molecular processes controlling gastrulation are well described in a variety of vertebrate species (Stern, 2004), mechanisms central to the mammalian gastrulation still need a proper interpretation, in particular the spatio-temporal cell behaviour in mammals with flat embryonic disc. A good candidate for this study is the rabbit model characterized by late implantation and mammotypical embryonic disc which is morphologically and topographically similar to the flat embryo of the chick; in this way the rabbit embryo may serve as a conceptual 'bridge' connecting birds and mammals.

The work presented in this thesis uses the rabbit blastocyst with its special characteristics and aims to elucidate the following questions: (1) how do cells become reorganized to form and shape the primitive streak, and subsequently (2) which morphogenetic mechanisms guide the early phase of mammalian gastrulation, i.e. primitive streak elongation and node formation. Possibly, analysis of morphogenetic mechanisms during primitive streak formation in the rabbit embryo may even help to understand the evolutionary pathway of gastrulation forms that have led to the emergence of the primitive streak as a 'pivotal innovation' of the gastrulation process. 


\section{Methods Summary}

New Zealand White rabbit blastocysts were flushed from uterine horns immediately prior to gastrulation, on day 6 after conception.

Cell movements were recorded for up to four hours with a Leica TCS SP2 confocal microscope and a Carl Zeiss Axiovert 200M inverted microscope using twophoton effect and differential interference contrast (DIC), respectively. Prior to timelapse recording with the confocal microscope, blastocysts were stained with $1 \mu \mathrm{g} / \mathrm{ml}$ DAPI in equilibrated medium for 1 hour.

For interfering with cell movements, blastocysts were treated with $10-100 \mu \mathrm{M}$ Y-27632 for inhibition of Rho-associated protein kinase or with $0.5-2.5 \mu \mathrm{M}$ latrunculin A (LatA) for inhibition of actin polymerization in culture medium over night or for six hours, respectively.

In situ hybridization for Brachyury and Chordin mRNA, staining of hyaluronan and F-actin, as well as scanning and transmission electron microscopical (SEM and TEM) analysis, of control and treated whole-mount embryonic discs, were carried out following standard protocols.

Set-ups for injection and electroporation (CellTram vario system, Eppendorf) were adapted to the specifications of the rabbit blastocyst (see subchapter 3.3).

For statistical analysis of the measured metaphase plates against the A-P axis, Rao's test was used which was cross-checked by Monte-Carlo simulation (Halacheva et al., 2011, see 7.1). Image analysis was carried out with ImageJ and Adobe Photoshop CS3 software.

For full methods, see chapters 'Experimental Procedures' of the first paper (see 7.1) and 'Supplementary Material' of the manuscript (see 7.2). 


\section{Results Summary}

\subsection{Planar Cell Movements and Oriented Cell Division}

In the paper entitled 'Planar cell movements and oriented cell division during early primitive streak formation in the mammalian embryo' (see 7.1), live tracking of individual neighbouring cells was shown by means of two-photon and Nomarski (DIC) time-lapse microscopy with the following results: Epiblast cells were found to perform so-called L- and U-turns as well as intercalation-like 'processional cell movements' leading to medio-lateral narrowing of embryonic tissue in the posterior gastrula extension (PGE) area, and subsequently to A-P elongation of the primitive streak. Cell proliferation was suggested to play an important role, in particular with specific orientation of metaphase plates (chromosomes lying in the equatorial plane) in the PGE area, i.e. the metaphase plates tended to be aligned parallel to the A-P axis of the embryonic disc. Moreover, immediately prior to anaphase (separation of chromosomes) high significance levels for orientation of metaphase plates were obtained using statistical analysis. Thus, preferred orientation of dividing cells was proposed to be essential for the progress of primitive streak elongation. In addition, single metaphase plates rotated rapidly at up to $45^{\circ}$ per minute, suggesting that 'last-minute' rotation may have a correcting role for achieving a preferred orientation.

\subsection{Axial Patterning Following Experimentally Modified Cell Movements}

In the manuscript entitled 'Tracing ancestral gastrulation through modified cellular movements in the mammalian embryo' (see 7.2), gastrulation cell movements were intentionally disturbed using a specific inhibitor of the PCP pathway (Y-27632) which blocks the Rho-associated protein kinase (ROCK). This resulted in radial spreading of cell movements instead of L- and U-turns. In addition, interfering with cell movements using the ROCK-inhibitor led to: (1) strikingly disturbed primitive streak morphology followed by embryonic growth in width (medio-lateral direction) as seen in DIC timelapse movies, (2) ectopic mesoderm formation in a dose-dependent manner which was reminiscent of gastrulation centres in amphibian (blastopore), reptiles (blastopore and primitive plate) and teleost fish (embryonic shield) as seen by abnormal Brachyury 
expression patterns and (3) intact organizer region and, hence, dorso-ventral patterning in ROCK-inhibited embryos which retained regular morphology of the notochord with typical Chordin expression. Furthermore, experiments with latrunculin A (LatA) showed severely affected actin cytoskeleton in the whole embryo causing defective cytokinesis and cell movements. Thus, the application of LatA highlighted the specific effect of ROCK inhibition on the PCP-dependent cell movements which were restricted to the PGE area only. In short, this manuscript confirms the major role of cell movements during the early gastrulation and reveals new cellular mechanisms of primitive streak modification suggesting that slight differences in these cellular mechanisms may explain the evolution of gastrulation centres from the ancestral blastopore to the modern primitive streak.

\subsection{Unpublished Data Related to Planar Cell Movements}

\subsubsection{Transfection of Rabbit Blastodisc}

To investigate mechanisms important for planar cell movements and axis formation at the molecular level, experiments involving electroporation of plasmid DNA as a potent interfering factor were carried out. In a first series of experiments $(n=10), 60 \%$ of the extraembryonic tissue (trophoblast) showed GFP-positive cells whereas only $15 \%$ of the embryonic disc were successfully transfected after microinjection and electroporation of enhanced green fluorescent protein plasmid (pEGFP; $2 \mu \mathrm{g} / \mathrm{ml}$ ) under the zona pellucida in various embryonic and extraembryonic areas of the rabbit blastocyst (Figure 3-1).

To interfere with the Wnt-signalling pathway, constructed plasmids - prickleGFP (Ciruna et al., 2006) and Dickkopf-GFP (Weisheit, 2003) - were electroporated; however, these transfections were not successful as far as no GFP signal or morphogenetic changes were observed using either of the two plasmids. 

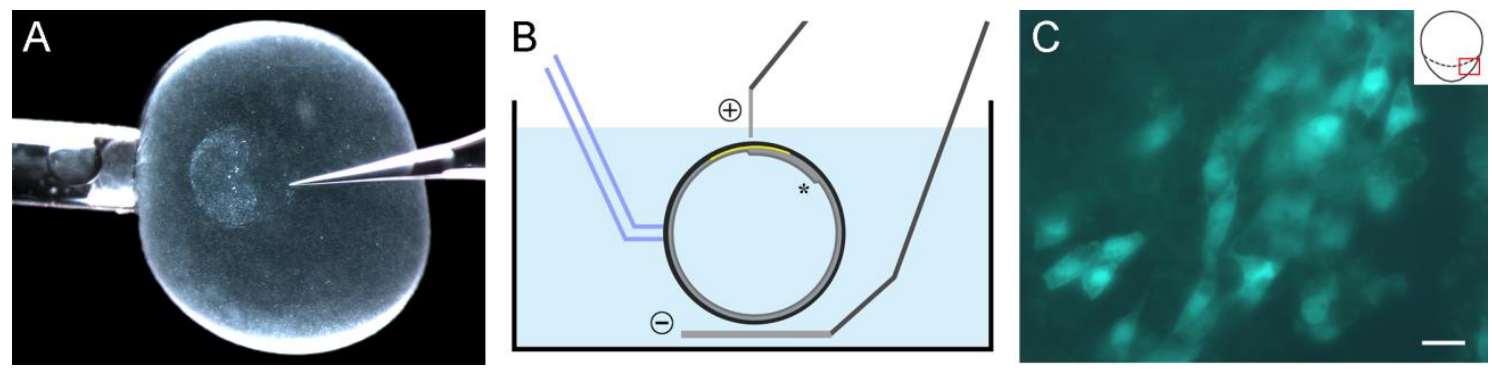

Figure 3-1: Electroporation of a rabbit blastocyst

(A) In vivo microinjection of plasmid DNA, under the zona pellucida. (B) Electroporation set-up of whole rabbit blastocysts. After injecting the pEGFP, three $10 \mathrm{~ms}$ pulses of $5 \mathrm{~V}, 1000 \mathrm{~ms}$ apart using a TSS20 Ovodyne electroporator (IntraCel) were applied. An asterisk marks the anterior border of the embryonic disc. Yellow colour marks injected plasmid DNA whereas the blue-coloured lines illustrate a glass pipette which holds the blastocyst in position during the procedure. (C) GFP-positive cells in the posterior area of the embryonic disc. Scale bar: A $-440 \mu \mathrm{m}, \mathrm{B}-220 \mu \mathrm{m}, \mathrm{C}-20 \mu \mathrm{m}$.

\subsubsection{Orientation of 'Beaded Threads'}

Ultrastructural analysis via scanning electron microscopy (SEM) of the dorsal surfaces of four rabbit embryonic discs showed a relatively large number of intercellular bridges connecting daughter cells, the so-called 'beaded threads' (Bellairs and Bancroft, 1975) which are the result of a delayed separation after telophase (Figure 3-2). Remarkably, the longitudinal axis of most 'beaded threads' detected here coincided with the preferred orientation of cell divisions with respect to the A-P axis described previously using DAPI stained blastocysts (Halacheva et al., 2011, see 7.1). However, the possible changes in the orientation of the 'beaded threads' during the period immediately after the onset of gastrulation as well as the fate of the daughter cells during the migration of neighbouring cells still need to be described in detail. In addition, the challenging question about the function and the life-cycle of these 'beaded threads' still remains to be resolved. 

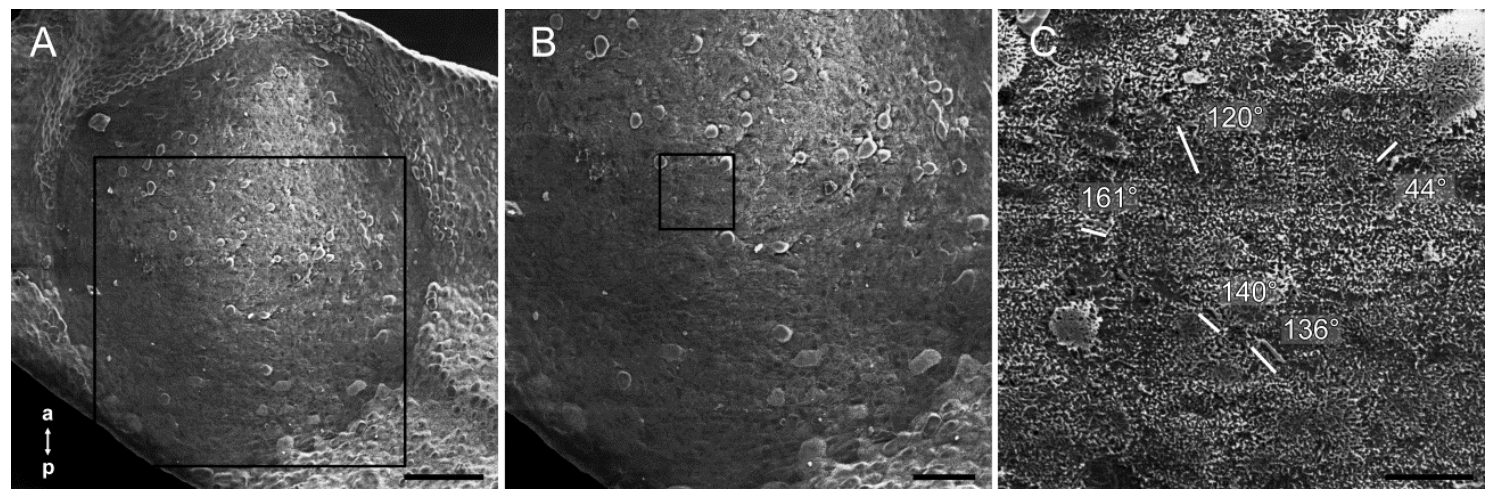

Figure 3-2: Scanning electron microscopic analysis of 'beaded threads' in a pre-gastrulating rabbit embryo

(A-C) Dorsal views of a rabbit embryonic disc photographed with magnification factors as follows: A $\mathrm{x} 160, \mathrm{~B}-\mathrm{x} 250$ and $\mathrm{C}-\mathrm{x} 1800$. Black boxes in A and B indicate the position of the regions shown in B and $\mathrm{C}$, respectively. White lines in $\mathrm{C}$ show the length and the orientation of the 'beaded threads' towards the transversal (medio-lateral) axis. Scale bar: A - $100 \mu \mathrm{m}, \mathrm{B}-50 \mu \mathrm{m}, \mathrm{C}-10 \mu \mathrm{m}$.

\subsubsection{Extracellular Matrix}

Molecules involved in the extracellular matrix have been suggested as important regulators of intercellular signals or, indeed, as effectors of cell movement influencing epiblast cell displacements (Chuai and Weijer, 2009; Zamir et al., 2008). To investigate

a possible role of the extracellular matrix for the gastrulation in the rabbit model, a recombinant neurocan-GFP protein which binds on hyaluronan (HA), was used (Zhang et al., 2004). The neurocan-GFP staining revealed mosaic distribution of HA in epiblast as well as in hypoblast cells which might be interpreted as a sign of an individual composition of the extracellular matrix for the various types of cellular movements, e.g. L- and U-turns and 'processional cell movements'; thus, individual cells or group of cells might be controlled by different mechanisms. An additional an intriguing finding was that the neurocan-GFP also stained the mitotic spindle of many - but not all dividing epiblast cells (Figure 3-3). However, only exact mapping of cell movements regarding the mosaic distribution of $\mathrm{HA}$ and the intracellular localization of the PCP proteins may confirm a putative role of the extracellular matrix for directed cell movements prior to gastrulation. 

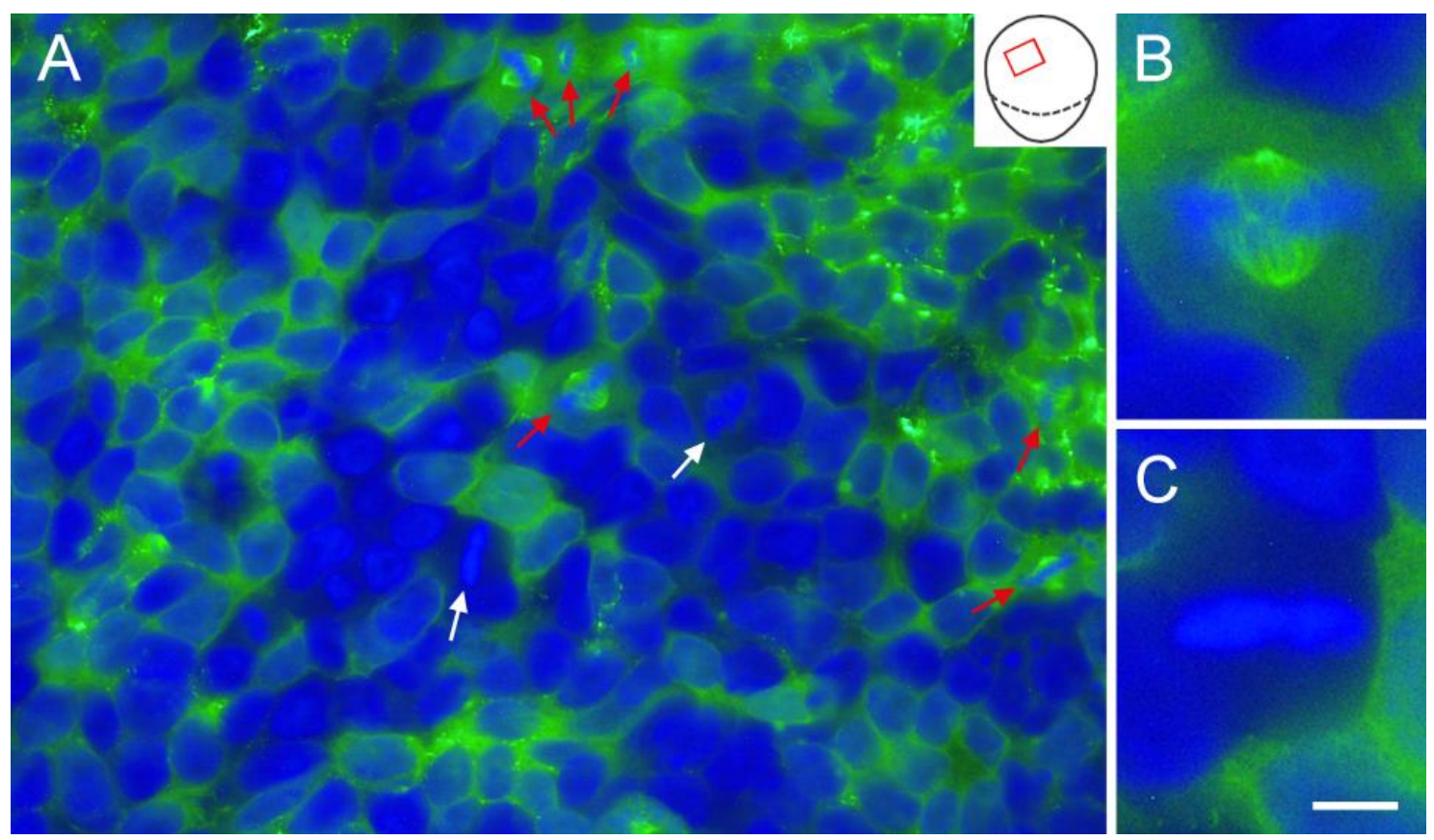

Figure 3-3: Double-staining of a whole-mount rabbit embryonic disc for hyaluronan and cell nuclei

(A) Red arrows point to neurocan-GFP-stained mitotic spindles whereas white arrows indicate metaphase plates without stained mitotic spindles. Red box on the schematic drawing in the right upper corner marks the position of the area shown in A in the anterior half of the embryonic disc. (B) Magnified view of a neurocan-GFP-positive mitotic spindle. (C) Magnified view of a metaphase plate whose mitotic spindle is negative for neurocan-GFP. Scale bar: $\mathrm{A}-20 \mu \mathrm{m}, \mathrm{B}$ and $\mathrm{C}-7 \mu \mathrm{m}$. 


\section{Discussion}

This doctoral thesis provides evidence for the importance of planar cell movements in forming and lengthening of the mammalian primitive streak: Prior to and after onset of gastrulation, L- and U-turns are complemented by 'processional cell movements' and oriented cell divisions as well as by inverted L- and U-turns. In addition, experimental interference with cell movements through inhibition of the PCP pathway causes formation of a circular (ancestral) gastrulation centre instead of a band-like primitive streak while dorso-ventral patterning remains undisturbed. For details also refer to 7.1 and 7.2.

\subsection{Cell Movements vs. Cell Divisions}

The coordination of specific cellular movements and oriented cell divisions was described here for the first time in a living mammotypical blastodisc and suggests a close relation between both cellular mechanisms required for correct axis formation. For example, prior to the emergence of the primitive streak, L- and U-turn cell movements were supported by 'processional cell movements' and oriented cell divisions which were required for cell accumulation in the 'cell-poor' PGE area; this is in contrast to the chick situation. The novel mode of 'processional cell movements' allows a rapid supply of cells in the area of the presumptive primitive streak through cells passing between their neighbours - a cellular mechanism that has not been described in the chick embryo (cf. Voiculescu et al., 2007). In the latter, 'processional cell movements' are probably not needed due to the already existing cell density in the Koller's sickle at this stage. In the rabbit embryo, cell divisions which were oriented perpendicular to the A-P axis in the PGE area only, play a supporting role as well, i.e. similar to the 'processional cell movements', cell divisions obtaining preferred orientation prior to the separation of the daughter cells, maintain the cell density in the PGE area. Here, we suggested that cell density achieved prior to the streak formation plays a role as a depot for cells which need to be translocated to more posterior areas of the embryonic disc during the later stage of gastrulation. At that stage, inverted L- and U-turn cell movements allow the elongation of the primitive streak.

The role of cell division in the primitive streak formation still remains controversial considering the various opinions regarding one species, e.g. zebrafish (cf. 
Concha and Adams, 1998 vs. Kessel R.G., 1960) or chick embryo (cf. Bodenstein and Stern, 2005; Chuai et al., 2006 vs. Wei and Mikawa, 2000). Indeed, recent studies on zebrafish gastrulation suggested that cell divisions have a specific orientation which is also PCP-dependent (Gong et al., 2004); however, the importance of the oriented cell divisions for the tissue elongation still has to be experimentally proved. In the chick, in contrast, the contribution of cell divisions to primitive streak elongation has not been confirmed (Bodenstein and Stern, 2005; Chuai et al., 2006).

Thus, despite the highly oriented cell divisions in the PGE region, cell movement may remain the most prominent mechanism driving primitive streak formation in the rabbit as well; this was secondly proved using the inhibitory substances Y-27632 and LatA which led to disturbed gastrulation cell movements and subsequently to failure of axis formation. However, prior to proposing a hypothesis, similar inhibition of cell divisions, as in the chick embryo (Chuai et al., 2006), at the same gastrulation stage is required in the rabbit model to ensure the 'outstanding' role of cell movements.

\subsection{ROCK-dependent Actin Remodelling Controls Cell Movements}

In order to examine the major role of planar cell movements during gastrulation, a specific inhibitor of ROCK - a downstream effector of the Wnt-PCP pathway (Uehata et al., 1997) - was used to interfere with this signalling cascade. Here, the spatial information encoded by PCP proteins (e.g. Frizzled and others) is transferred into actin cytoskeleton remodelling due to the activation of ROCK by Dishevelled and Daam1 (Habas et al., 2001; Winter et al., 2001). Thus, PCP-ROCK signalling plays crucial roles: (1) in cell movements during gastrulation and neurulation in zebrafish (Weiser et al., 2009), chicken (Henkels et al., 2013; Wei et al., 2001) and mouse embryo (Mahaffey et al., 2013; Yen et al., 2009) and (2) in mesoderm formation during the EMT process (Nakaya et al., 2008). Activated ROCK phosphorylates LIM kinase and myosin light chain (MLC) phosphatase which are associated with actin polymerization and actomyosin contractility, respectively. Therefore, inhibition of ROCK causes cytoskeleton changes which in turn influence the morphogenetic cell movements such as $\mathrm{CE}$ and cell intercalation, and subsequently disturb the axis elongation (Bertet et al., 2004; Simoes Sde et al., 2010). Referring to this, 'centrifugal' patterns of cell movements seen in rabbit embryos treated with ROCK inhibitor might be explained by the loss of cell polarity through rearrangement of actin cytoskeleton; this was confirmed 
by ectopic actin distribution in the epiblast cells from the PGE area only, using phalloidin staining. In addition, the widened form of the gastrulation centre (or the primitive streak) in treated rabbit embryos is consistent with earlier data in the mouse which reported a similar effect after using the same inhibitory compound Y-27632 (Greene et al., 1998; Ybot-Gonzalez et al., 2007). Indeed, in the mouse, actin remodelling is required for initiation of the PCP pathway, e.g. for vesicular trafficking of PCP proteins to the apical membrane, although it is not required for the further process of planar polarization (Mahaffey et al., 2013). Now, the widened gastrulation centre of treated rabbit embryos showing abnormal actin distribution needs to be studied in detail; in particular, it is important to examine whether a probable co-localization of 'clump-like' actin distribution presented here is existing with the PCP proteins, and consequently to define the role of actin cytoskeleton in the planar cell polarization of the typical mammalian embryo.

On the other hand, lack of actomyosin contractility which is also affected by ROCK inhibition has been shown to disturb tissue elongation and growth restriction in width in Drosophila (He et al., 2010). Thus, the actomyosin contractility is perhaps a 'mechanical force' that might also drive axis elongation in higher vertebrates. We suggest that reduced actomyosin contractility might be responsible for the probably slower speed of the cell movements in rabbit embryos treated with ROCK inhibitor (V.S., unpublished data).

A comparison of experiments with ROCK inhibitor and LatA confirmed that both interfere with the PCP-ROCK pathway in a different fashion. For example, the LatA which binds actin monomers severely affected the actin cytoskeleton in the whole embryonic disc whereas the ROCK inhibitor affected specifically the cell population from the PGE only. In addition, the LatA treatment resulted in completely blocked embryonic development whereas the ROCK inhibition did not prevent vital cellular processes, e.g. in the case of the latter, cell movements and cell divisions as well as mesoderm ingression (EMT) were still possible. Taking all these observations into account, our mammalian system appears to possess similar mechanisms for regulation of primitive streak elongation through the PCP pathway by ROCK-dependent actin reorganization. 


\subsection{Ancestral-like Gastrulation Centre}

Broadened Brachyury-expressing patterns seen in rabbit embryos treated with low concentration of ROCK inhibitor were compared with the ectopic Brachyury-expressing crescent of Wnt-PCP disturbed chick embryos (cf. Voiculescu et al., 2007). Intriguingly, Voiculescu and co-authors proposed that this broad area marked by Brachyury-expressing mesoderm cells could be compared with the amphibian blastopore. In addition to this hypothesis, the data presented in the manuscript (see 7.2) verifies a possible analogy between PCP-disturbed rabbit embryos and their ancestors, especially with the various dose-dependent Brachyury-expressing patterns illustrating the gastrulation centres in amphibians and reptiles (also possessing a primitive plate, cf. Bertocchini et al., 2013) or even in zebrafish. Moreover, we suggest that adapted cellular mechanisms, for example reduced speed of cell movements, might drive formation of gastrulation centres in lower vertebrates.

Interestingly, the idea that the primitive streak - as a longitudinal structure could be non-essential for the mesoderm formation as suggested by Alev and co-authors via subgerminal injection of FGF in birds (Alev et al., 2013), may be also adequate for the situation in the mammalian gastrulation centre, e.g. the mesoderm induction occurs independently of the modified primitive streak area or the so-called widened gastrulation centre (see 7.2).

\subsection{Evolution of the Mammalian Primitive Streak}

Comparative studies on morphogenesis of gastrulation in vertebrates including mammals suggested that the primitive streak of the mammalian embryo is an analogue to the blastopore of lower vertebrates (Kollmann, 1886). This similarity was mainly based on the fact that both structures have the same function in embryonic development. However, cellular mechanisms, confirming the resemblance of the ancestral blastopore and the novel primitive streak still remain undistinguished.

Indeed, the gastrulation of metazoan is guided by the same mechanism - cell movement - which is a basic mechanism for the formation of the body axes (Wolpert, 1992). In addition, the 'conserved' morphogenetic movements may diverge throughout the evolution due to the various forms of the embryos and the amount of yolk (Elinson, 1987). For example, the increase of yolk which is characteristic for the eggs of bony fishes, reptiles, birds and primitive mammals - in contrast to amphibians - was 
suggested to be the main factor driving the 'rearrangement' of gastrulation (Arendt and Nubler-Jung, 1999).

The present doctoral thesis supports the hypothesis of the gastrula evolution through increase of yolk, and in addition, provides a possible explanation for the formation of the mammalian primitive streak through intense and complex cell movements; here we suggest that slight changes in the 'conserved' cellular motility might be enough to drive the evolution of the ancestral 'blastopore gastrulation mode' to the novel 'primitive streak gastrulation mode'. 


\section{Conclusion}

This doctoral thesis provides new insights into cellular behaviour with regard to axial patterning prior to and during gastrulation of the early mammalian embryo. The unsuspected complexity of cell movements and preferential orientation of mitotic figures in the area of the prospective primitive streak suggests a close link between both morphogenetic processes. However, the individual role of cell divisions during axis formation in the rabbit embryo still needs to be experimentally proved. Additionally, this may help to understand the complex cell behaviour during the mammalian streak formation. However, this thesis already suggests that molecular mechanisms as the PCP pathway may control the early mammalian development through cellular mechanisms as actin remodelling. Therefore, an exact link between these morphogenetic mechanisms needs to be established, in particular by using the possibilities of the rabbit embryo and interfering experimentally with various molecular factors, e.g. through injection of inhibitors and transfection of plasmid DNA. In addition, ancestral gastrulation forms - instead of the typical primitive streak - which were seen in rabbit embryos with impeded cell movements provide evidence for cellular mechanisms diverging throughout the vertebrate phylum, and thus may drive the evolution of gastrulation. Hence, similar studies on species in which the gastrulation centre is represented by both blastopore and streak-like primitive plate as seen in the reptiles, are required to confirm this evolutionary hypothesis. The rabbit - representing a 'prototypical' mammalian gastrula - may, therefore, become a key model organism for understanding the mechanisms controlling early mammalian development as well as the evolution of embryonic development. 


\section{References}

Alev, C., Wu, Y., Nakaya, Y., Sheng, G., 2013. Decoupling of amniote gastrulation and streak formation reveals a morphogenetic unity in vertebrate mesoderm induction. Development 140, 2691-2696.

Arendt, D., Nubler-Jung, K., 1999. Rearranging gastrulation in the name of yolk: evolution of gastrulation in yolk-rich amniote eggs. Mech. Dev. 81, 3-22.

Bellairs, R., Bancroft, M., 1975. Midbodies and beaded threads. Am J Anat 143, 393398.

Bernard, C., 1859. Leçons sur les propriétés physiologiques et les altérations pathologiques des liquides de l’organisme. Paris, Baillière.

Bertet, C., Sulak, L., Lecuit, T., 2004. Myosin-dependent junction remodelling controls planar cell intercalation and axis elongation. Nature 429, 667-671.

Bertocchini, F., Alev, C., Nakaya, Y., Sheng, G., 2013. A little winning streak: the reptilian-eye view of gastrulation in birds. Dev. Growth Differ. 55, 52-59.

Bodenstein, L., Stern, C.D., 2005. Formation of the chick primitive streak as studied in computer simulations. J. Theor. Biol. 233, 253-269.

Chuai, M., Weijer, C.J., 2009. Who moves whom during primitive streak formation in the chick embryo. HFSP journal 3, 71-76.

Chuai, M., Zeng, W., Yang, X., Boychenko, V., Glazier, J.A., Weijer, C.J., 2006. Cell movement during chick primitive streak formation. Dev. Biol. 296, 137-149.

Ciruna, B., Jenny, A., Lee, D., Mlodzik, M., Schier, A.F., 2006. Planar cell polarity signalling couples cell division and morphogenesis during neurulation. Nature 439, 220-224.

Concha, M.L., Adams, R.J., 1998. Oriented cell divisions and cellular morphogenesis in the zebrafish gastrula and neurula: a time-lapse analysis. Development 125, 983994.

Cui, C., Yang, X., Chuai, M., Glazier, J.A., Weijer, C.J., 2005. Analysis of tissue flow patterns during primitive streak formation in the chick embryo. Dev. Biol. 284, $37-47$. 
Elinson, R.P., 1987. Changes in developmental patterns: embryos in amphibians with large eggs. In: R.A. Raff R.A., Raff, E.C. (Eds.), Development as an Evolutionary Process. Alan R. Liss, NY, 1-21.

Gong, Y., Mo, C., Fraser, S.E., 2004. Planar cell polarity signalling controls cell division orientation during zebrafish gastrulation. Nature 430, 689-693.

Greene, N.D., Gerrelli, D., Van Straaten, H.W., Copp, A.J., 1998. Abnormalities of floor plate, notochord and somite differentiation in the loop-tail (Lp) mouse: a model of severe neural tube defects. Mech. Dev. 73, 59-72.

Habas, R., Kato, Y., He, X., 2001. Wnt/Frizzled activation of Rho regulates vertebrate gastrulation and requires a novel Formin homology protein Daam1. Cell 107, 843-854.

Halacheva, V., Fuchs, M., Donitz, J., Reupke, T., Puschel, B., Viebahn, C., 2011. Planar cell movements and oriented cell division during early primitive streak formation in the mammalian embryo. Dev. Dyn. 240, 1905-1916.

He, L., Wang, X., Tang, H.L., Montell, D.J., 2010. Tissue elongation requires oscillating contractions of a basal actomyosin network. Nat. Cell. Biol. 12, 11331142.

Henkels, J., Oh, J., Xu, W., Owen, D., Sulchek, T., Zamir, E., 2013. Spatiotemporal mechanical variation reveals critical role for rho kinase during primitive streak morphogenesis. Ann. Biomed. Eng. 41, 421-432.

Keller, R., Danilchik, M., 1988. Regional expression, pattern and timing of convergence and extension during gastrulation of Xenopus laevis. Development 103, 193-209.

Kessel, R.G., 1960. The role of cell division in gastrulation of Fundulus heteroclitus. Exp. Cell. Res. 20, 277-282.

Kollmann, J., 1886. "Gastrulasitzung" der 59. Versammlung deutscher Naturforscher und Ärzte zu Berlin. Anat. Anz. 1: 281-294.

Lawson, A. and Schoenwolf, G. C., 2003. Epiblast and primitive-streak origins of the endoderm in the gastrulating chick embryo. Development 130, 3491-3501.

Mahaffey, J.P., Grego-Bessa, J., Liem, K.F., Jr., Anderson, K.V., 2013. Cofilin and Vangl2 cooperate in the initiation of planar cell polarity in the mouse embryo. Development 140, 1262-1271. 
Nakaya, Y., Sukowati, E.W., Wu, Y., Sheng, G., 2008. RhoA and microtubule dynamics control cell-basement membrane interaction in EMT during gastrulation. Nat. Cell. Biol. 10, 765-775.

Seifert, J.R., Mlodzik, M., 2007. Frizzled/PCP signalling: a conserved mechanism regulating cell polarity and directed motility. Nat. Rev. Genet. 8, 126-138.

Simoes Sde, M., Blankenship, J.T., Weitz, O., Farrell, D.L., Tamada, M., FernandezGonzalez, R., Zallen, J.A., 2010. Rho-kinase directs Bazooka/Par-3 planar polarity during Drosophila axis elongation. Dev. Cell 19, 377-388.

Stern, C.D., 2004. Gastrulation. Cold Spring Harbor Laboratory Press, Cold Spring Harbor, NY, USA.

Tam, P.P., Behringer, R.R., 1997. Mouse gastrulation: the formation of a mammalian body plan. Mech. Dev. 68, 3-25.

Uehata, M., Ishizaki, T., Satoh, H., Ono, T., Kawahara, T., Morishita, T., Tamakawa, H., Yamagami, K., Inui, J., Maekawa, M., Narumiya, S., 1997. Calcium sensitization of smooth muscle mediated by a Rho-associated protein kinase in hypertension. Nature 389, 990-994.

Viebahn, C., Mayer, B., Miething, A., 1995. Morphology of incipient mesoderm formation in the rabbit embryo: a light- and retrospective electron-microscopic study. Acta Anat (Basel) 154, 99-110.

Viebahn, C., Stortz, C., Mitchell, S.A., Blum, M., 2002. Low proliferative and high migratory activity in the area of Brachyury expressing mesoderm progenitor cells in the gastrulating rabbit embryo. Development 129, 2355-2365.

Voiculescu, O., Bertocchini, F., Wolpert, L., Keller, R.E., Stern, C.D., 2007. The amniote primitive streak is defined by epithelial cell intercalation before gastrulation. Nature 449, 1049-1052.

Warga, R.M., Kimmel, C.B., 1990. Cell movements during epiboly and gastrulation in zebrafish. Development 108, 569-580.

Wei, L., Roberts, W., Wang, L., Yamada, M., Zhang, S., Zhao, Z., Rivkees, S.A., Schwartz, R.J., Imanaka-Yoshida, K., 2001. Rho kinases play an obligatory role in vertebrate embryonic organogenesis. Development 128, 2953-2962.

Wei, Y., Mikawa, T., 2000. Formation of the avian primitive streak from spatially restricted blastoderm: evidence for polarized cell division in the elongating streak. Development 127, 87-96. 
Weiser, D.C., Row, R.H., Kimelman, D., 2009. Rho-regulated myosin phosphatase establishes the level of protrusive activity required for cell movements during zebrafish gastrulation. Development 136, 2375-2384.

Weisheit, G., 2002. Molekulare Differenzierung und Musterbildung im Hypoblasten während der embryonalen Frühentwicklung des Kaninchens. Cuvillier, Göttingen.

Williams, M., Burdsal, C., Periasamy, A., Lewandoski, M., Sutherland, A., 2012. Mouse primitive streak forms in situ by initiation of epithelial to mesenchymal transition without migration of a cell population. Dev. Dyn. 241, 270-283.

Winter, C.G., Wang, B., Ballew, A., Royou, A., Karess, R., Axelrod, J.D., Luo, L., 2001. Drosophila Rho-associated kinase (Drok) links Frizzled-mediated planar cell polarity signaling to the actin cytoskeleton. Cell 105, 81-91.

Wolpert, L., 1992. Gastrulation and the evolution of development. Dev. Suppl., 7-13.

Ybot-Gonzalez, P., Savery, D., Gerrelli, D., Signore, M., Mitchell, C.E., Faux, C.H., Greene, N.D., Copp, A.J., 2007. Convergent extension, planar-cell-polarity signalling and initiation of mouse neural tube closure. Development 134, 789799.

Yen, W.W., Williams, M., Periasamy, A., Conaway, M., Burdsal, C., Keller, R., Lu, X., Sutherland, A., 2009. PTK7 is essential for polarized cell motility and convergent extension during mouse gastrulation. Development 136, 2039-2048.

Zamir, E.A., Rongish, B.J., Little, C.D., 2008. The ECM moves during primitive streak formation--computation of ECM versus cellular motion. PLoS biology 6, e247.

Zhang, H., Baader, S.L., Sixt, M., Kappler, J., Rauch, U., 2004. Neurocan-GFP fusion protein: a new approach to detect hyaluronan on tissue sections and living cells. J. Histochem. Cytochem. 52, 915-922. 


\section{Publications}

\subsection{Published Paper}

'Planar Cell Movements and Oriented Cell Division during Early Primitive Streak Formation in the Mammalian Embryo'

Viktoriya Halacheva ${ }^{1}$, Mathias Fuchs ${ }^{2}$, Jürgen Dönitz ${ }^{2}$, Tobias Reupke ${ }^{1}$, Bernd Püschel $^{1}$ and Christoph Viebahn ${ }^{1}$

${ }^{1}$ Department of Anatomy and Embryology, Centre of Anatomy, University of Göttingen, Germany

${ }^{2}$ Department of Bioinformatics, Centre of Informatics, Statistics and Epidemiology UMG, University of Göttingen, Germany

Author contributions:

V.H., T.R., B.P. and C.V. designed protocols and experiments; V.H. carried out the experiments; V.H., T.R. and C.V. analyzed the data; M.F. and J.D. carried out the statistical analyses; V.H., M.F., J.D. and C.V. wrote the manuscript. 


\title{
Planar Cell Movements and Oriented Cell Division During Early Primitive Streak Formation in the Mammalian Embryo
}

\author{
Viktoriya Halacheva, ${ }^{1}$ Mathias Fuchs, ${ }^{2}$ Jürgen Dönitz, ${ }^{2}$ Tobias Reupke, ${ }^{1}$ \\ Bernd Püschel, ${ }^{1}$ and Christoph Viebahn ${ }^{1 *}$
}

Formation of the mammalian primitive streak appears to rely on cell proliferation to a minor extent only, but compensating cell movements have not yet been directly observed. This study analyses individual cell migration and proliferation simultaneously, using multiphoton and differential interference contrast time-lapse microscopy of late pregastrulation rabbit blastocysts. Epiblast cells in the posterior gastrula extension area accumulated medially and displayed complex planar movements including U-turns and a novel type of processional cell movement. In the same area metaphase plates tended to be aligned parallel to the anterior-posterior axis, and statistical analysis showed that rotations of metaphase plates causing preferred orientation were near-complete $8 \mathrm{~min}$ before anaphase onset; in some cases, rotations were strikingly rapid, achieving up to $45^{\circ}$ per min. The mammalian primitive streak appears to be formed initially with its typically minimal anteroposterior elongation by a combination of oriented cell divisions with dedicated planar cell movements. Developmental Dynamics 240:1905-1916, 2011. $\odot 2011$ Wiley-Liss, Inc.

Key words: cell movements; metaphase plate orientation; axial differentiation

Accepted 2 June 2011

\section{INTRODUCTION}

Cell proliferation and cell movement are fundamental prerequisites for the early embryonic development of multicellular organisms. During vertebrate gastrulation, which brings about the formation of the body axes and the differentiation of germ layers, they can be considered as two antipodes of cellular activity which start and maintain morphogenesis before the formation of tissues with specialized fate or function. Elegant studies in teleost fish (Montero et al., 2005; Olivier et al., 2010) recently confirmed basic concepts of morphogene- sis which had been formulated previously in amphibians (Vogt, 1925; Keller, 2002) and, most importantly, they identified molecular factors that regulate this process (Ulrich et al., $2003,2005)$. In comparison, the analogous development in amniote embryos is less well understood, which is partly due to the reduced accessibility of equivalent stages in the egg or intrauterine environment. However, in analogy to the amphibian blastoporus and teleost marginal zone, the primitive streak has a particularly complex function as the first irreversible axial structure in amniotes: It is about to launch into both germ layer formation and vigorous growth acceleration of the embryo. While the dynamics of primitive streak formation in reptiles are still largely unresolved (cf. Gilland and Burke, 2004; Coolen et al., 2008), the clear picture known for avian primitive streak morphogenesis (Voiculescu et al., 2007) cannot be extrapolated to the mammalian situation because the starting points for primitive streak formation differ fundamentally: The chick embryo has a pre-existing cell density at the posterior marginal zone, also known as Koller's sickle (Koller, 1882; Stern,

Additional Supporting Information may be found in the online version of this article.

${ }^{1}$ Department of Anatomy and Embryology, Centre of Anatomy, University of Göttingen, Germany

${ }^{2}$ Department of Bioinformatics, Centre of Informatics, Statistics and Epidemiology UMG, University of Göttingen, Germany

Grant sponsor: Deutsche Forschungsgemeinschaft; Grant number: Vi 151/8-1.

*Correspondence to: Christoph Viebahn, Georg-August-Universität Göttingen, Department of Anatomy and Embryology,

Kreuzbergring 36, 37075 Göttingen, Germany. E-mail: christoph.viebahn@medizin.uni-goettingen.de

DOI 10.1002/dvdy.22687

Published online 13 July 2011 in Wiley Online Library (wileyonlinelibrary.com). 
1990; Callebaut and Van Nueten, 1994); accordingly, cell movements associated with epithelial cell intercalation are highly responsible for rearrangement of an existing cell mass (Voiculescu et al., 2007) and hence appear to have a role predominant to that of cell proliferation (Sanders et al., 1993). Contrastingly, in the mammalian embryo the primitive streak forms in an area with a relative lack of cells compared with the rest of the embryo, namely in the socalled posterior gastrula extension (PGE) area (rabbit: Viebahn et al., 2002; pig: Hassoun et al., 2009; mouse: s. Fig. 1A in Downs and Davies, 1993; human: s. Fig. 18 in Luckett, 1978); as cell proliferation is not a prominent feature in the PGE area, cell migration from the anterior two-thirds of the embryonic disc instead compensates for the lack of cells in the early phase of primitive streak formation, and proliferation sets in only after the primitive streak has formed (Viebahn et al., 2002). Therefore, the net balance between migration and proliferation may tip toward migration in both amniote groups, but the paths taken by individual cells are still likely to differ in a crowded (aves) vs. a rarefied (mammalia) situation.

In addition to cell movement, the orientation of dividing cells can have a defined direction relative to the embryonic axes and may, therefore, have an important function in axial elongation (Hydra: Shimizu et al., 1995) or in determining organ shape (Drosophila wings: Strutt, 2005; mouse kidney tubules: Fischer et al., 2006; vertebrate limb buds: Wyngaarden et al., 2010). Indeed, during gastrulation and at the beginning of neurulation in zebrafish, cell divisions in the epiblast are highly aligned (Concha and Adams, 1998; Gong et al., 2004) such that orientation of the mitotic spindles is parallel to the long axis. In chick embryos, the mitotic spindles are preferentially orientated parallel to the long axis of the embryo at early streak stages (Wei and Mikawa, 2000), during early neurulation (Sausedo et al., 1997) and during notochord extension (Sausedo and Schoenwolf, 1993), thus possibly contributing to axial elongation (see how- ever, Bodenstein and Stern, 2005). But no reports appear to exist on oriented cell division during the formation of the primitive streak in the mammalian embryo although the marked differences in overall cell numbers and the topography of cell densities between mammals and birds mentioned above make direct observations in mammals a necessity.

While cell movements can be readily observed live in the chick embryo (Wei and Mikawa, 2000; Cui et al., 2005; Voiculescu et al., 2007), a similar approach is more difficult in mammals due to their intra-uterine development and, in the case of rodents, due to a complex morphology, e.g., the cup-shaped egg cylinder during gastrulation (Tam and Gad, 2004). Cell movements in the mouse embryo are consequently defined for the cells in the anterior visceral endoderm (Perea-Gomez et al., 2001; Srinivas et al., 2004; Kwon et al., 2008; Burtscher and Lickert, 2009) and for the intra-embryonic tissues such as the epiblast only after the onset of gastrulation (Nakatsuji et al., 1986; Lawson et al., 1991; Yamanaka et al., 2007; Yen et al., 2009). Late implantation and the flat embryonic disc of the rabbit allowed indirect demonstration of extensive planar cell movements of the epiblast layer by using the live marker DiI injected between epiblast and zona pellucida at the late pregastrulation stage (Viebahn et al., 2002). However, given the negligible quantitative effect of local proliferation in the primitive streak forming area of the rabbit (Viebahn et al., 2002), the question of individual cell behavior before primitive streak formation arises, if only to find mechanisms which regulate this cell behavior at a qualitative level. The current study, therefore, intends to analyze cell movement and cell division at the onset of gastrulation simultaneously, using multiphoton time-lapse imaging of rabbit blastocysts developing in vitro. The results may answer questions as to how epiblast cells move to form the primitive streak in a mammotypical flat embryonic disc and whether proliferation contributes to primitive streak formation by orienting metaphase plates specifically according to the pre-existing anterior-posterior (A-P) axis.

\section{RESULTS \\ Morphological Development in Culture}

Embryos about to be cultured were at stage 2, i.e., at the developmental stage immediately before the formation of the primitive streak; they revealed their A-P polarization in two specific landmarks: (1) the sharp anterior contour of the anterior marginal crescent (AMC) and (2) the reduced cellular density of the PGE (cf. Fig. 1A), where the primitive streak is about to be formed. The oil drop used as constant mark of the posterior pole during culture appeared as a bright round spot under semi-dark field illumination (Fig. 1B). After a recording session and following overnight culture (16 $\mathrm{hr}$ ), embryonic discs had developed to stage 3 with a typical increased cellular density at the anterior periphery of the AMC and a distinct primitive streak in the posterior half of the embryonic disc (Fig. 1C).

Epiblast and hypoblast, the two cell layers present at the late preprimitive streak stage, were distinguishable by their nuclear form, size and relative number when focusing on either of both layers using multiphoton microscopy of the DAPI (4',6-diamidine-2phenylidole-dihydrochloride) -stained blastocysts: Close to the zona pellucida surface of the embryonic disc, nuclei are oval, smaller and approximately three times as numerous as compared to those found in the layer near the blastocyst cavity, which are characterized by their large and round shapes (cf. Fig. 1D,E). Accordingly, the cells with the small nuclei were assigned to the epiblast, while the larger nuclei were assigned to hypoblast cells. For the purpose of this study, only the cells in the epiblast were considered, whereby individual cells had to be followed through several focal planes (see the Experimental Procedures section) during the period of time-lapse recording.

\section{Cell Movement}

Using multiphoton time-lapse microscopy with a time resolution of $5 \mathrm{~min}$ and an overall duration of $2 \mathrm{hr}$, several types of cell movement within the PGE were observed. Observation 
periods started either approximately 4 or $2 \mathrm{hr}$ after, or immediately following, the injection of the positional oil drop marker and DAPI staining (s. Experimental Procedures). In this way, a 6 -hr period of the early primitive streak forming process was accessible for direct observation. Traces of individually marked nuclei revealed overall symmetrical movements with respect to the A-P axis on both sides of the embryonic disc (see Fig. 2A-C and Supp. Movie S1), while the position of the embryo-as judged from the still pictures showing the oil drop marker at the beginning and at the end of the recording sessionremained stationary. The trajectories of lateral cells were generally longer than those close to the midline. Thus, the more lateral cells performed socalled "L-turns" (Fig. 2C), i.e., a posterior movement followed by a movement from either side toward the midline. In contrast, many complex posterior-anterior cell movements near the midline were characterized as "U-turns" whose absolute movement is toward the presumed area of the primitive streak. At the end of their U-turns, some of the medial cells disappeared from the plane of focus toward the hypoblast layer.

Detailed tracing of individual neighboring cells near to, and in, the area of the presumptive primitive streak regularly revealed a new type of cell movement: In a group of three adjacent cells one cell (labeled "a" in Fig. 2D-F) distinctly changed its position posteromedially during the period of observation (90 $\mathrm{min}$ in this case), while its two immediate neighbors ("b" and "c") moved apart and converged again after cell "a" had passed between them. The movement of cell "a" across the virtual line connecting cells "b" and "c" goes further than during conventional mediolateral intercalation: Here, three cells may start to change their relative positions in a similar way but passing between cells has not been described so far (cf. Voiculescu et al., 2007). As the passing of cell " $a$ " is reminiscent of a procession-like step on the dance floor (a metaphor which had been used before with the figure of "polonaise" and "double-whirl" movements, cf. Gräper, 1929, and Wetzel, 1929) this movement is described here as "processional cell movement" (PCM). This new type of movement occurred mainly near the center of the PGE, i.e., in the area of the emerging primitive streak, and was less frequently observed in lateral parts of the PGE (s. Fig. 2G and the distribution of PCM cases in Supp. Movie S2). Net movement of processional cells was posteromedial when observed in the lateral part of the PGE and predominantly medial when observed near the center of the PGE (cf. orientation of vectors in Fig. 2G).

As shapes and boundaries of individual epiblast cells during PCM were clearly visible in differential interfering contrast (DIC) movies, too (s. Fig. 3A-F and Supp. Movie S3), the complete sequence of PCM could be observed to consist of the following steps: (1) neighboring cells " $b$ " and "c" loosen their broad and close contact (cf. bracket in Fig. 3B) completely, (2) let the processional cell "a" pass between them, and (3) re-establish close contact, again. Of interest, the necessary protrusion of a leading edge of the processional cell "a", including the formation of a new contact zone (cf. bracket in Fig. 3C) with a fourth cell lying ahead on the processional path, was accomplished within less than 5 min (cf. Fig. 3B,C).

In a quantitative analysis, all cases of neighbor cell changes observed between any three cells of which the central cell "a" showed posteromedial or medial translocation were recorded by "dynamic triangulation" (see Supp. Movies S2, S3, and S4) within every movie and subsequently divided into four classes as follows (Supp. Fig. S1): (1) conventional intercalation, whereby the triangular connection between the centers of neighboring cells changes from a more-or-less even shape to an elongated shape and junctions between these cells change directionally as described previously (Bertet et al., 2004; Zallen and Blankenship, 2008), (2) "grade 1" PCM, whereby the processional cell passes the connecting line between its neighbors but the latter two cells do not (yet) come to lie together again (here, the original evenshaped triangle "collapses" into a single line and then changes into an inverted elongated shape), (3) "grade 2" PCM, which corresponds to complete PCM and is defined by the emergence of a completely inverted even-shaped triangle at the end of neighbor change movement, and (4) "potential end phase" of PCM, which is defined by the change from an elongated triangle to an even shaped triangle (Supp. Fig. S1 is available online). The total number of cases within these classes was compared by calculating different ratios $\left(R_{1}, R_{2}\right.$ and $R_{3}$ ) between the numbers of occurrence of conventional intercalation and that of different PCM subclasses (Suppl. Table S1). Ratios indicated that PCM was two to three times as frequent as conventional cell intercalation (cf. $R_{2}$ and $R_{3}$ in Supp. Table S1). For instance, the ratio $R_{2}$ between the number of occurrences of conventional intercalation to that of "grade 1" and "grade 2" PCM was counted across all embryos to be 18:37, which corresponds to a $P$ value of $P=0.0145$.

\section{Orientation of the Late Metaphase Plates}

In time-lapse movies of DAPI-stained blastocysts, metaphase plates were visible as small lines in the equatorial plane of cells about to enter anaphase. As the angle of cell division became rapidly obscured soon after anaphase, the orientations of the metaphase plates were determined in the last image taken before the anaphase, i.e., $5 \mathrm{~min}$ at most before anaphase onset which was considered to coincide with the appearance of two parallel lines in the following image (cf. Fig. 4E,F). The angles between these late metaphase plates and the A-P axis, which was defined by the position of the AMC, were measured in 351 cells from six embryos and plotted in a rose diagram (Fig. 5A); most of these angles lay in a range around zero (between $-45^{\circ}$ and $45^{\circ}$ ) with a maximum of cases near $25^{\circ}$. The angular variance was 0.8 with $P$ value $=$ 0.0036 compared with a uniform distribution; the average angle enclosed between late metaphase plates and the A-P axis was $8.8^{\circ}$ (Supp. Table S2). Although the angles scattered broadly, statistical analysis revealed that an orientation in a range of angles parallel to the A-P axis was the preferred orientation.

Alignment of late metaphase plate positions from six embryos revealed that there was correspondence between 


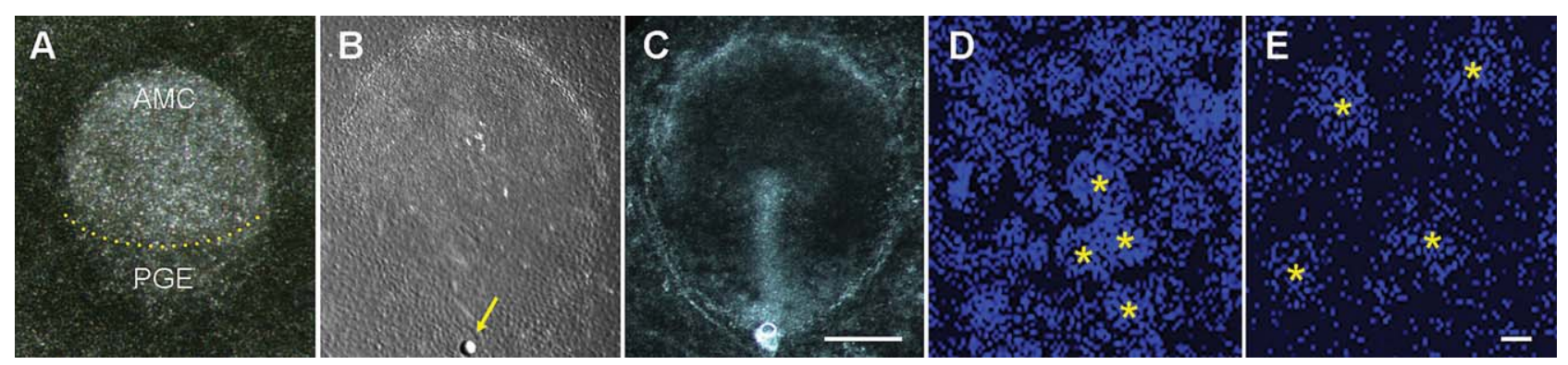

Fig. 1.

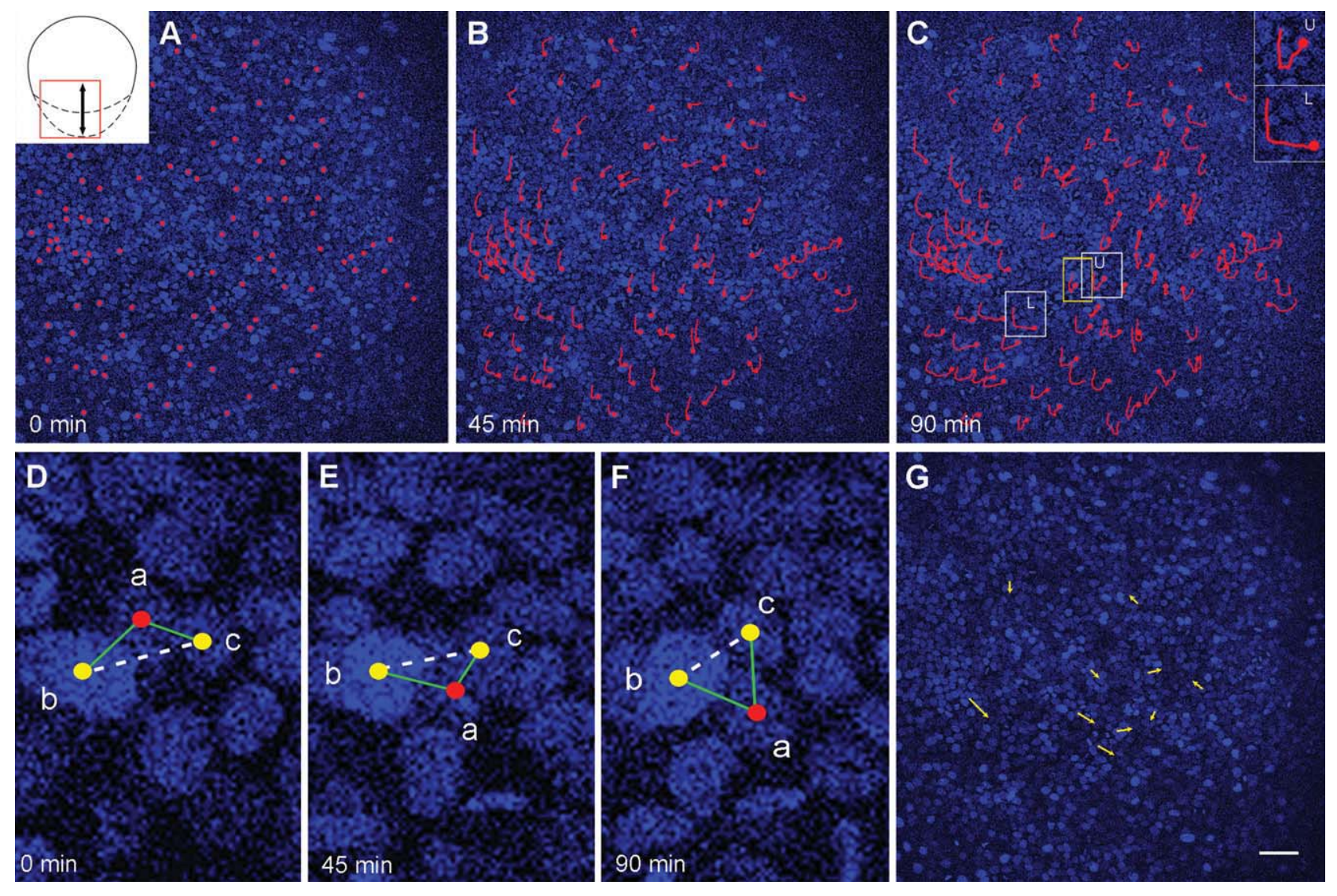

Fig. 2.
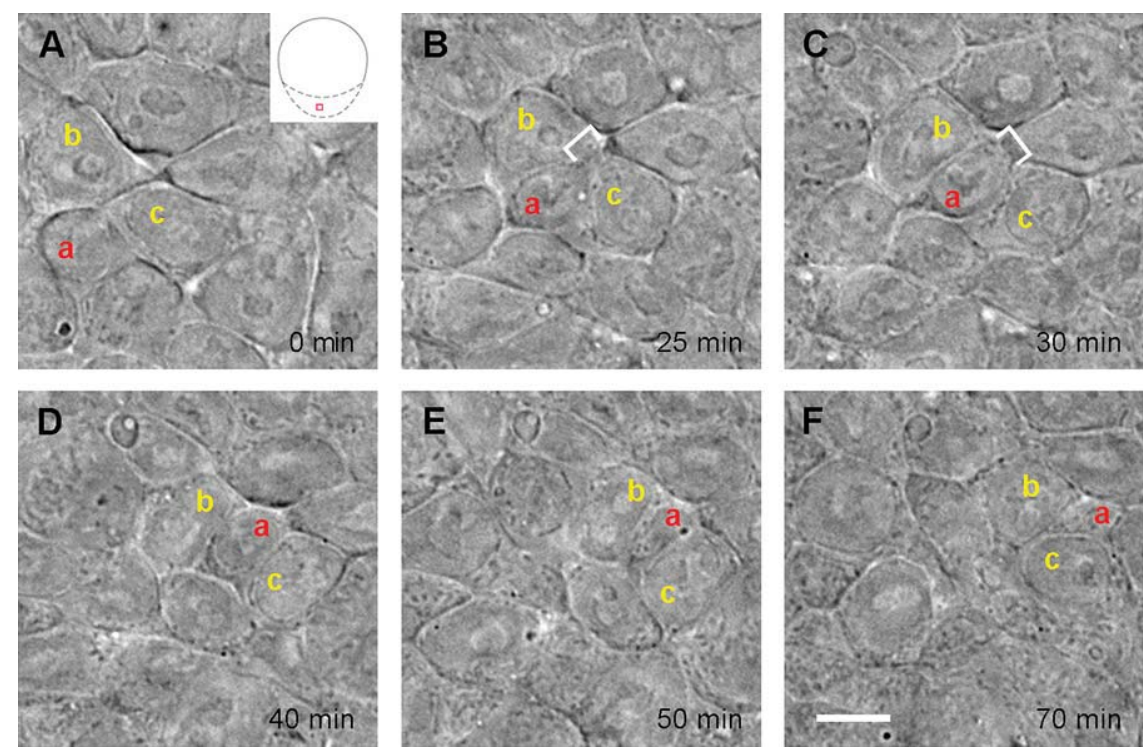

Fig. 3. 
the angles of the metaphase plates and their position along the A-P axis (Fig. 5B). Indeed, visual inspection also showed that the angles were mostly smaller in the PGE area than those in the anterior part of the embryonic disc, referred to here as "nonPGE area." In fact, the orientation preference of the metaphase plates in the PGE area was found to be statistically significant while the metaphase plates from the non-PGE area were not shown to have a preferred orientation (cf. Fig. 5C,D). The angular variance of the former group differed significantly from that of a uniform distribution while that of the latter did not (Supp. Table S2). Moreover, the plot of the positions of the metaphase plates along the mediolateral axis against their angles with the A-P axis showed that metaphase plates with small angles accumulated near to the center of the embryonic disc (Fig. 6).

\section{Metaphase Plate Rotation}

During observation periods in which a particular mitosis could be continuously recorded using multiphoton microscopy of DAPI-stained blastocysts, the orientation of individual metaphase plates varied markedly and the movies showed that this was due to isolated rotation of metaphase plates rather than to curved migration of cells in metaphase (cf. Fig. 4C,E). Overt rotations occurred most frequently during the early metaphase whereas during the late metaphase, i.e., approximately $10 \mathrm{~min}$ before anaphase, no major rotation movements were detected. Instead, many rotations showed switches between clockwise (cf. Fig. 4C,D) and counter-clockwise rotation (cf. Fig. 4E,F), similar to an oscillating movement.

Because the low time resolution that had to be used for the DAPI movies was too coarse to study small rotatory movements or the exact angular speed, time-lapse DIC microscopy (Nomarski contrast) was performed at intervals of $40 \mathrm{sec}$. Here, epiblast and hypoblast were distinguishable by the cell size and the intercellular space in both layers, e.g., the cells of the epiblast are smaller and the space between adjacent epiblast cells is narrower than in the hypoblast (not shown). In these DIC movies, metaphase plates appeared as a bulging chromosome mass forming a broad bar that changed orientation during metaphase (s. Fig. 7A-L and Supp. Movie S5). For most metaphase plates observed in these DIC movies, the rotation was a relatively slow process that took place throughout early metaphase (30-10 min before anaphase). However, the metaphase plates of a few mitotic cells turned rapidly within a 120 -sec period during late meta- phase (cf. Fig. 7D,F), a movement which also included small oscillating movements described above (for clockwise rotation cf. Fig. 7A and B, B and $\mathrm{C}, \mathrm{F}$ and $\mathrm{G}$; for counter-clockwise rotation cf. Fig. $7 \mathrm{C}$ and D, D and E, I and $\mathrm{J}$ ); the total resulting angle of these fast rotations was regularly more than $90^{\circ}$ (Fig. $7 \mathrm{~K}$ ).

For a chronometrical analysis of all metaphase plate rotations observed in two DIC recordings, an average absolute rotation value within single 40sec time periods was calculated (Fig. $7 \mathrm{M})$. In this way, two time periods were distinguishable: An early one, 14 to approximately $8 \mathrm{~min}$ before the onset of anaphase, showed higher average rotation values, whereas a second subsequent one, less than $8 \mathrm{~min}$ before anaphase, exhibited distinctly lower average rotations of the metaphase plates. Separate analysis of cells from the PGE and non-PGE areas revealed no differences in the rotation values of metaphase plates between these embryonic compartments (not shown).

The high time resolution of the DIC recordings revealed the exact timing of metaphase plate rotations with reference to anaphase onset. As a result, all cells from the PGE area whose metaphase plates were visible for a minimal 11-min period could be tested statistically using the Rao test against the null hypothesis of a

Fig. 1. Dorsal views of the rabbit embryonic discs. A: Darkfield illumination of a living embryonic disc at stage 2 showing the anterior marginal crescent (AMC) and the posterior gastrula extension (PGE); the dotted line marks the anterior border of the PGE area. B: Semi-dark field illumination of an embryonic disc at stage 2 immediately following injection of an oil bead (yellow arrow) between the zona pellucida and the epiblast at the posterior pole. C: Dark field illumination of an embryonic disc developed to stage 3 after overnight culture. D: DAPI-stained epiblast cell nuclei at high magnification. E: DAPI-stained hypoblast cell nuclei at high magnification. Yellow asterisks indicate the center of nuclei. Scale bar $=50$ $\mu \mathrm{m}$ in $\mathrm{A}, \mathrm{C}, 32 \mu \mathrm{m}$ in $\mathrm{B}, 0.25 \mu \mathrm{m}$ in $\mathrm{D}, \mathrm{E}$.

Fig. 2. Planar epiblast cell movement in the posterior half of a late pre-streak embryonic disc. A-C: Three single frames from the time-lapse series (Supp. Movie S1) taken at intervals of 45 min. Red tracks mark the paths of individual epiblast cells, red dots show the position of a given cell at the time the current frame was taken. The red box in the schematic drawing of the upper left-hand corner indicates the position of the region shown in $(\mathrm{A}-\mathrm{C})$, the arrow being the projection of the stage 3 primitive streak position onto the posterior half of the stage 2 embryonic disc. In the upper right-hand corner two types of movements occurring in the posterior half of the primitive streak are shown at high magnification ( $U$, $U$-turns; $\mathrm{L}$, L-turns). The position of these paths is marked with white boxes in (C). D-F: processional cell movement (PCM) in the area of the prospective primitive streak taken from the same frames as shown in (A-C); the position of the selected area is indicated by a yellow box in (C). Three adjacent cells (marked "a" with a red dot and "b" and "c" both with yellow dots) are connected by lines; "b" and "c" are connected by a dotted line to highlight how cell "a" performs a procession-like movement past its two immediate neighbors. G: Vector diagram superimposed onto the frame shown in $(\mathrm{A})$ and depicting the position, frequency, direction and length of PCM in the posterior gastrula extension (PGE). The points of the arrows mark the end position of processional cells in this recording period. Scale bar $=50 \mu \mathrm{m}$ in $A-C, G, 5 \mu \mathrm{m}$ in $\mathrm{D}-\mathrm{F}$.

Fig. 3. Changing cell shapes during processional cell movement (PCM) as seen with differential differential interfering contrast (DIC) optics in the area of presumptive primitive streak (A-F). Six frames taken at different intervals highlight how neighboring cells "b" and "c" are intimately connected before (cf. A and bracket in B) and after (E) processional cell "a" passes or has passed between them. The short interval between the frames shown in $(B)$ and $(C)$ indicates the relative speed at which cell "a" protrudes its leading edge past cells "b" and "c" to make contact (bracket in C) with its "new" neighbor on the other side of cells "b" and "c." Schematic drawing in (A) indicates position of frames within the embryonic disc. Scale bar $=10 \mu \mathrm{m}$. 

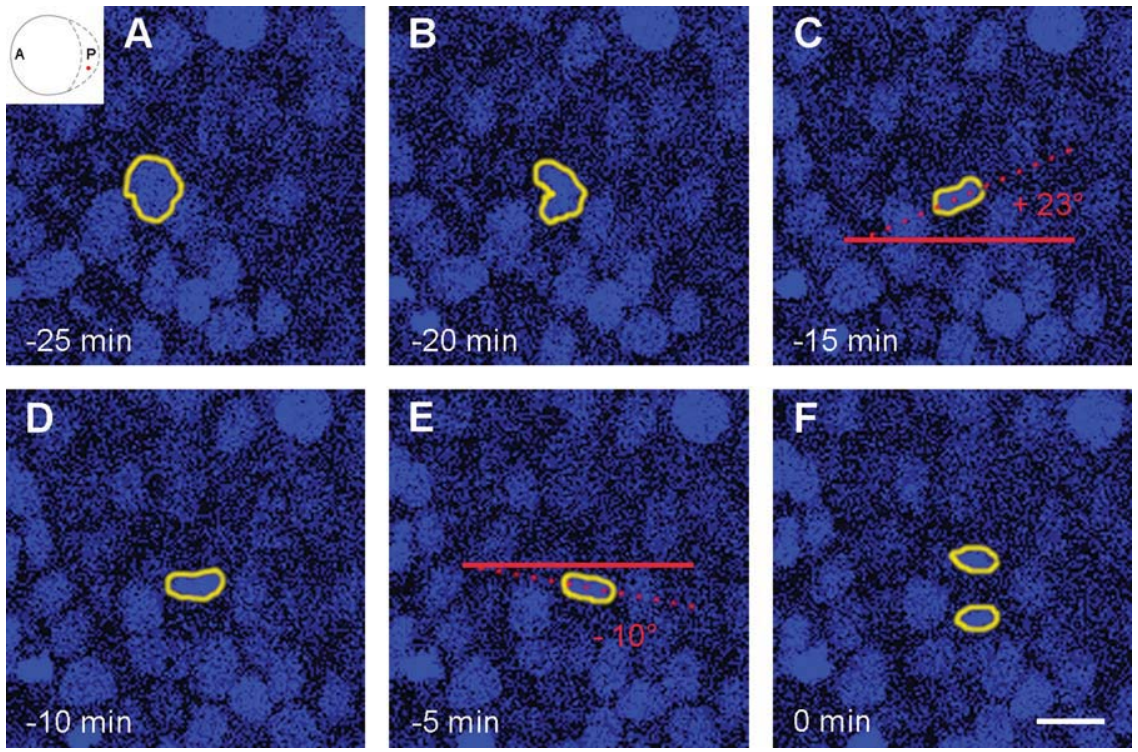

Fig. 4. Late metaphase plate angle definition. A-F: Single frames from a DAPI (4',6-diamidine2-phenylidole-dihydrochloride) time-lapse movie showing the change in orientation of a metaphase plate in the posterior gastrula extension (PGE) area in 5-min time intervals 25 min before anaphase. The outlines of the DAPI labeled DNA package (nuclei or metaphase chromosomes) of the dividing cell are marked by a yellow line and the angle of the metaphase plate with anterior-posterior (A-P) axis (solid red line) is indicated by a dotted red line. The red dot in the inset in (A) indicates the position of the dividing cell in the embryonic disc. Scale bar $=20 \mu \mathrm{m}$.
A

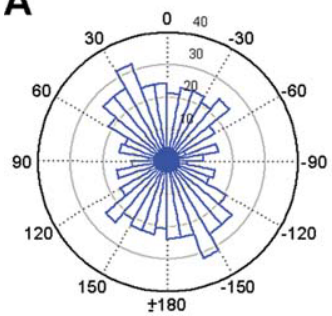

C

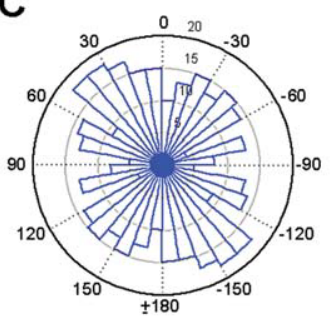

B

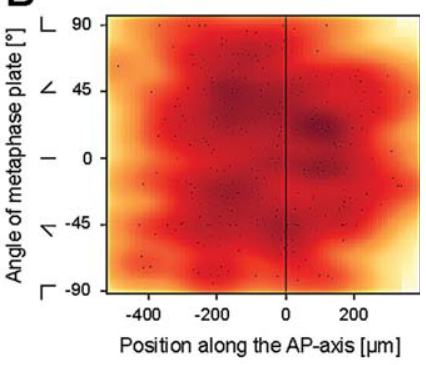

D

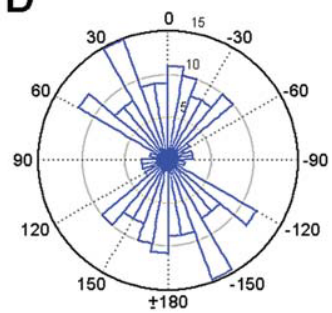

Fig. 5. Statistical analysis of late metaphase plate orientation. A: Rose diagram of 351 metaphase plate angles (taken from six embryos) grouped in intervals of $10^{\circ}$. The metaphase plates are taken from all areas of the embryonic disc. The anterior-posterior (A-P) axis is set to correspond with $0^{\circ}$, each angle $\alpha$ is shown together with its opposite angle $\left(\alpha+180^{\circ}\right)$ to produce a $360^{\circ}$ image mirrored at the line connecting the $+90^{\circ}$ and $-90^{\circ}$ values. B: Scatter plot of late metaphase plate angles against their position along the A-P axis. Positive values on the $\mathrm{X}$-axis represent metaphase plate positions in the posterior gastrula extension (PGE) area while negative values correspond to positions in the anterior part of the embryonic disc (non-PGE area). The $y$-axis denotes the angles of the metaphase plate. Colors represent the smoothened density of the data points, i.e., darker colors correspond to higher density. C: Rose diagram of 229 metaphase plate angles taken from the non-PGE area. D: Rose diagram of 122 metaphase plate angles taken from PGE area. uniform distribution. Ten cells from two embryos met these criteria and for these the distribution of metaphase plate angles was analyzed for each time-point recorded before anaphase. The plot of time before anaphase onset against $P$ value of the Rao test resulted in one set of significant and another of nonsignificant $P$ values (Fig. $7 \mathrm{~N}$ ): $8 \mathrm{~min}$ before anaphase, high significance levels for the orientation were attained, i.e., the time-point from which on the orientation preference was significant lay at least $440 \mathrm{sec}$ before anaphase onset. There was a clear-cut phase of decreasing $P$ values at around $8 \mathrm{~min}$ before anaphase and the last 12 timepoints showed a $P$ value of almost zero, corresponding to a preferred orientation of the metaphase plates relative to the A-P axis.

\section{DISCUSSION}

This time-lapse videomicroscopy analysis of whole rabbit embryos cultured in vitro provided direct evidence of cellular movements during the formation of the primitive streak, the overt longitudinal body axis, in the PGE area of the mammalian embryo: The emergence of the primitive streak is characterized by a combination of (1) complex individual cell movements including a new type of cell movement referred to here as processional cell movement (PCM), and (2) mitotic spindle rotations which ensure that the metaphase plates are aligned preferably parallel to the A-P axis.

\section{Multiphoton vs. DIC Time-Lapse Microscopy}

The combination of multiphoton fluorescence microscopy with conventional DIC microscopy was instrumental for identifying the characteristics of the spatial cell behavior in the first $6 \mathrm{hr}$ of primitive streak formation. Multiphoton microscopy of DAPI-stained blastocysts showed that the cells of the epiblast can be readily distinguished from those of the hypoblast by the different shape, size, and relative number of the nuclei, characteristics known from high-resolution histological studies of the same and other mammalian species including the mouse (cf. Viebahn, 1999; Eakin and 


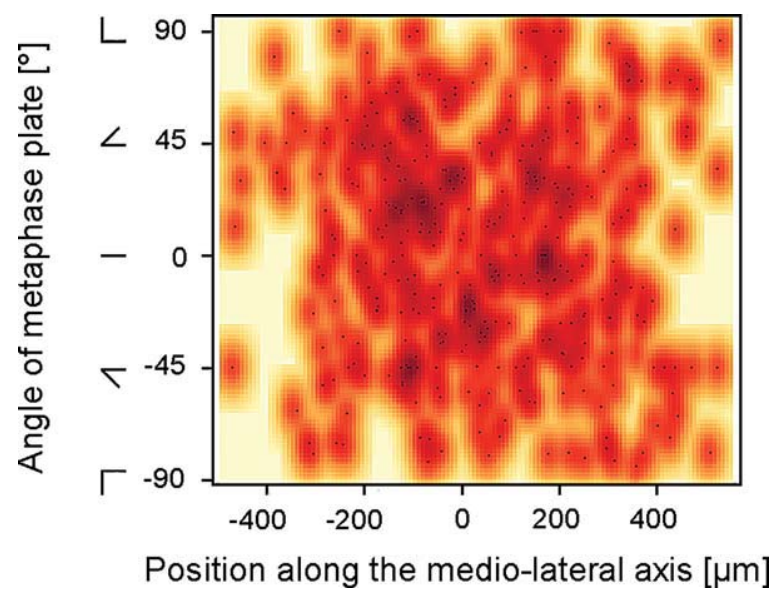

Fig. 6. Scatter plot of late metaphase plate angles against their position along the mediolateral axis. The plot was constructed analogously to the one of Figure 5B using data from whole embryonic discs and six embryos. The position along the mediolateral axis was mapped to the $x$-axis. The $x$-values represent the distance of the position of metaphase plates from the midline. The $y$-axis and the color coding are the same as those in Figure 5B.

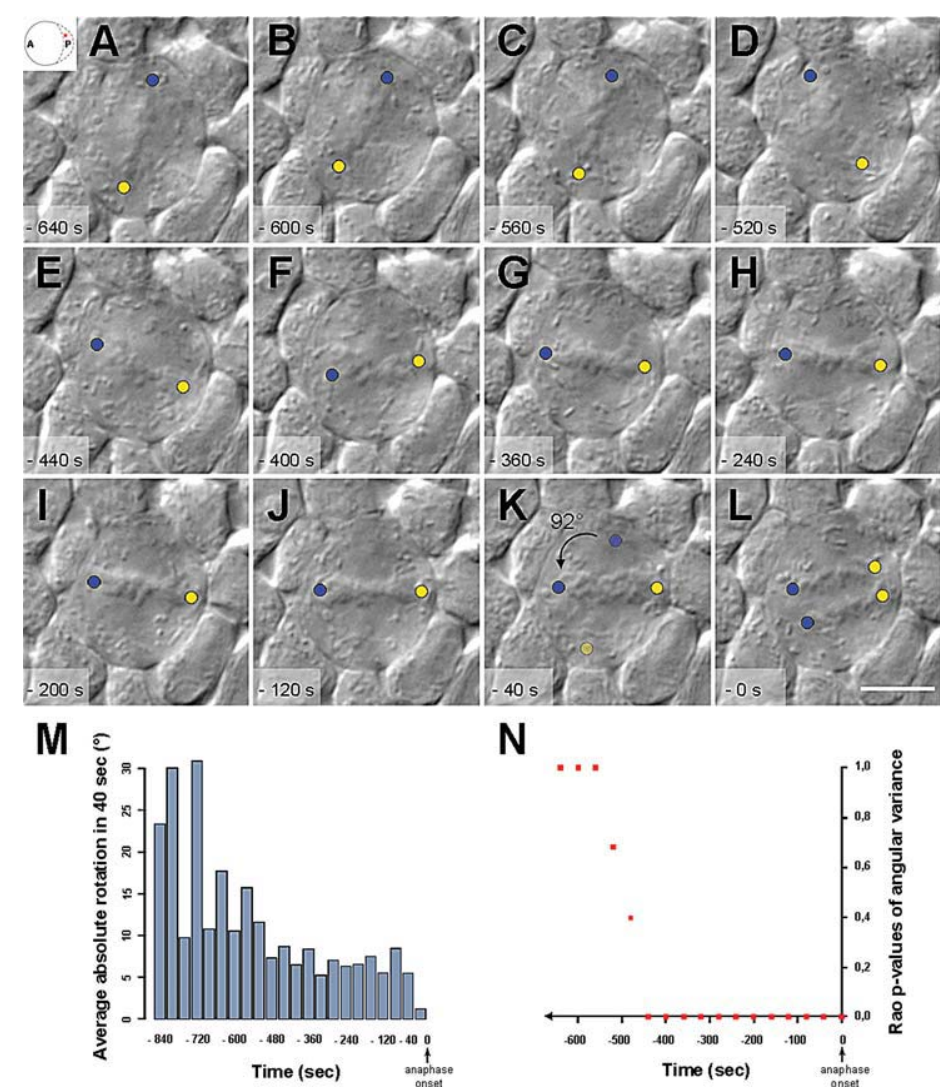

Fig. 7. Rotation of metaphase plates. A-L: Single frames from a differential interfering contrast (DIC) time-lapse movie (Supp. Movie S5) showing a dividing cell and the rapid rotation of its metaphase plate at 40-sec intervals; the position of this cell in the embryonic disc is indicated by the red dot in the inset in (A). A $92^{\circ}$ rotation (arrow in $\mathrm{K}$ ) of the metaphase plate can be seen when comparing the position of the metaphase plate extremities (yellow and blue dots) at the start of this recording $(A)$ and immediately prior $(K)$ to anaphase $(\mathrm{L})$. Scale bar $=20 \mu \mathrm{m}$. M: Average absolute rotation within a $40-\mathrm{sec}$ period (y-axis) at each time point before onset of anaphase (x-axis). $\mathrm{N}$ : Rao $P$ values of 10 mitotic cells taken from differential interfering contrast (DIC) time-lapse movies of two embryos ( $\mathrm{y}$-axis) at each time point before onset of anaphase (x-axis). The $P$ values were corrected for False Discovery Rate using the Benjamini-Hochberg procedure.
Behringer, 2004; Tam and Gad, 2004; Hassoun et al., 2009). A particular benefit of the DAPI-staining method is that almost all nuclei are visualized, which makes it possible to observe the metaphase plates throughout metaphase, whereas the DIC method enables one to observe the metaphase plates primarily at the late metaphase. However, the latter method allowed for use of shorter time intervals between consecutive images than the potentially cell damaging combination of DAPI-staining and multiphoton microscopy and was, therefore, instrumental for (1) verifying results obtained from the DAPI experiments, (2) defining cell membrane contact during PCM, and (3) defining the details and (high) speed of the mitotic spindle rotation and the exact timing of this rotation before the onset of anaphase.

\section{Cell Movement}

The two main paths taken by epiblast cells diverging from an apparently simple straight movement, the U- and L-turns (s. Fig. 2A-C), largely confirm the hypothesis of "polonaise" and "double whirl" movements in the PGE area toward the future primitive streak (Viebahn et al., 2002), movements which were originally described for the chick (Gräper, 1929; Wetzel, 1929). Cellular U-turns toward the posterior pole, however, were not observed in the present study possibly for two reasons: (1) Only the 6 initial hr of early primitive streak formation (stage 2) were captured in the movies of the present report and (2) the primitive streak elongates toward the anterior pole first before inverted U-turns are needed for lengthening of the primitive streak toward the posterior pole (stage 3). This posterior lengthening of the primitive streak is particularly apparent during the early stage 3 (as observed in some DIC movies, which allowed a longer exposition time than the DAPI movies; V.H., unpublished). The DiI tracings from which inverted U-turns were deduced (Viebahn et al., 2002), on the other hand, covered the complete period between stage 2 to 3 and recorded the cumulative effect of cell migration along cellular paths at the end the culture period. Lateral contraction of epiblast cells (which 
are rather flat in the PGE area: Viebahn et al., 1995) may also be a plausible mechanism to form the high and pseudostratified columnar epithelium near and in the primitive streak. However, structural signs of lateral contraction, i.e., a preferential narrowing of apical cell shapes along the transverse axis, are not seen in the DIC movies (cf. Supp. Movies S3, S4, and S5).

PCM, as the new type of planar cell movement found by time-lapse imaging of individual cells in the present study, is a movement based on the changes in the relative position of adjacent cells by which the "processional cell" crosses the boundary between its neighbors (see Supp. Movies S2, S3, S4 and Supp. Fig. $\mathrm{S} 1 \mathrm{~B}, \mathrm{C})$. In contrast, mediolateral cell intercalation observed in the epiblast of the pregastrulation chick embryo (Voiculescu et al., 2007) was based on the changes in the relative positions of non-neighboring cells in different regions, thus showing effects caused by more general cell movements. Therefore, the behavior of neighboring cells immediately before gastrulation in the rabbit requires the new definition given above and could be suitably described as a sub- (or micro-) movement of global (or macro) "polonaise" movements.

In the rabbit embryo, the major net movement leading to primitive streak formation appears not to be simply a mass "polonaise" and "double whirl" movement or conventional mediolateral cell intercalation, but a combination of mainly two variations of trajectory paths (U- and L-turns) and by PCM, the new type of cell movement (cf. Fig. 2). Both PCM and conventional intercalation are preferentially localized in the presumptive primitive streak area and therefore, they may functionally correlate with cell accumulation. However, PCM seems to be more frequent compared with conventional intercalation as ratios amount up to values of 2.9 , depending on the stringency with which they are calculated (cf. Supp. Table S1). A conservative calculation $\left(R_{2}=2.1\right)$ takes only cases of proven PCM into account, i.e., "grade 1 " and "grade 2 " PCM, in which cell "a" has moved beyond the connecting line between its immediate neighbors "b" and "c". This suggests already that neither conventional intercalation nor oriented epithelial contraction (s. above) but PCM may be a main mechanism, in addition to mass "polonaise" and "double whirl" macro-movements, for cell accumulation in the presumptive primitive streak forming area. In addition, the re-approaching of neighbor cells "b" and "c" during the end phase of PCM may help avoiding any elongation in the A-P plane at this early stage of primitive streak formation. Moreover, the extensive movement of a cell passing between its neighbors ("grade 2" PCM) may be a sign of the increased distance that individual cells have to move from the highly proliferative belt in the nonPGE area (cf. Fig. 7C in Viebahn et al., 2002) to the center of the "rarefied" PGE area. In the chick, in contrast, with its high cellular density in Koller's sickle and with its apparent lack of proliferation in the primitive streak forming area (Sanders et al., 1993), the additive effects of classical convergent extension movements may be necessary for (1) increasing the cellular density in the primitive streak and (2) for the transformation of the circular posterior pole of the embryonic disc into an elongated pear-shape (Voiculescu et al., 2007).

A functional prerequisite for PCM is planar polarization of the cells involved which may be conveyed by the signals of the PCP pathway (Zallen, 2007). Initially, attempts at determining the distribution of Vangl2 or Prickle1, two members of the PCP pathway expressed in or near the primitive streak of chick (cf. Zhang and Levin, 2009) and mouse (Suriben, 2009), in the rabbit embryonic disc have so far been unsuccessful (V.H., unpublished observations). However, global molecular factors controlling PCP and cell migration such as Wnt5a or Wnt11 (Gong et al., 2004; Ulrich et al., 2005) and Dkk1, a regulatory factor acting from a distance (Caneparo et al., 2007) and suitably expressed in the anterior marginal crescent (Idkowiak et al., 2004), can now be tested in a mammalian system on the basis of individual cell behavior described in the present report. In a different context, the fact that single cells pass their neighboring cells correlates with cells individually labeled for hyaluronan (V.H., unpublished observations), which has been shown to be instrumental in cell migration for tail regeneration (Contreras et al., 2009) and may be a further key factor in determining when cells move as singletons and when as a group (Arboleda-Estudillo et al., 2010).

\section{Analysis of Metaphase Plate Angles}

In comparison with previous studies measuring the orientation of mitotic spindles rather than the orientation of metaphase plates (Wyngaarden et al., 2010), the DAPI-staining approach taken in the present study allows for high precision measurements because the metaphase plates can be perceived as lines, rather than deducing orientation from lines through estimated cell centers. Taking into account the circular nature of the data, circular statistical representations were used. In principle, angles could also be mapped on to a linear scale and subsequently analyzed by linear statistics. However, a linear scale could divide two neighboring angle values to opposite ends of an interval; the variance would then depend on the cutting point which would lead to undesirable ambiguity; this ambiguity disappears through use of circular representation of statistical values.

The resulting rose diagrams do not always exhibit clear-cut peaks (Fig. $5)$; hence, the necessity to apply suitable statistics designed to yield precise information on preferred angles. However, the fact that statistical analyses of the orientation performed in this study show a less pronounced peak than those of other studies (e.g., Concha and Adams, 1998) could possibly be explained by the more complex cell movements in the rabbit (as compared to other model organisms) or by the relative uncertainty in determining the exact orientation of the A-P axis before emergence of the primitive streak: Obviously, this is particularly important in the mammalian embryo where the A-P axis as the reference for angle measurement before the appearance of the primitive streak has to be deduced from the estimated position of median AMC or PGE 
centers, i.e., the A-P axis cannot always be determined with the same degree of confidence as the axis of the primitive streak. This slight uncertainty in the position of the A-P axis may account for both the rather broad scattering of values (Fig. 5D) and the deviation (by approximately $8^{\circ}$ ) of the preferred metaphase plate orientation from a presumed "ideal" orientation exactly parallel to the A-P axis. However, these results may be taken at least as a first indication of oriented cell division before gastrulation in the mammalian embryo.

The first scatter plot (Fig. 5B) shows a clear pattern reflected by the data analysis, namely that the angles of the metaphase plates in the PGE are smaller (preferred parallel orientation) than those in the non-PGE area; this is also reflected by the markedly reduced number of large angles (i.e., white areas) in the righthand corners of the plot (Fig. 5B). In contrast, the second plot (Fig. 6) is more difficult to interpret. One of the reasons for this lies in the difficulty of ascertaining the location of the cells which are to form the primitive streak in the subsequent phase of development. Choosing a conservative estimate for the width of their location leads to the volume of data being too small for statistical analysis. However, the visual impression is that the small angles accumulate around the center of the plot, which would indicate that small angles tend to occur near the A-P axis.

\section{Oriented Cell Division}

In chick and zebrafish, the preferred orientation of the metaphase plates is perpendicular to the A-P axis (chick: Wei and Mikawa, 2000; zebrafish: Concha and Adams, 1998) and later, during neurulation, the orientation changes to a parallel direction (Concha and Adams, 1998). However, the orientation of cell divisions in the chick primitive streak forming area (Wei and Mikawa, 2000) appears to be in contrast with the present report; but its functional significance for primitive streak formation had earlier been questioned on the basis of a mathematical model (Bodenstein and Stern, 2005). Differences in spindle orientation between gastrulating chick and rabbit embryos may come as no surprise because of the marked disparity in overall size, cell numbers and the topography between the two species at this stage. The preferred orientation of the metaphase plates approximately parallel to the A-P axis, as observed in this study, seems to be advantageous for achieving a high cell density in the region of the presumptive primitive streak, similar to the effect of PCM in this area: Daughter cells divide along the mediolateral axis in an area in which neither A-P elongation (because of the early stage) nor mediolateral widening of the embryonic disc was detected, i.e., the dividing cells accumulate in the area of the primitive streak without deformation (e.g., widening) of the embryonic disc. This is supported by the mechanical effect which the lateral embryonic disc borders may have on tissue flow as cells arriving at these borders through oriented cell division have to move toward the midline because the borders limit lateral migration. In addition, movements of lateral cells (s. above L-turns) toward the presumptive primitive streak coincide with the movements of lateral daughter cells to increase this net medial cellular movement.

\section{Metaphase Plate Rotation}

Planar rotation before anaphase onset has previously been described as a mechanism for achieving defined orientation; in fact, misorientation of the mitotic spindles in normal rat kidney cells is corrected by direct rotation of the spindles (O'Connell and Wang, 2000). More closely related to axis formation, the rotation of mitotic spindles establishes a preferred orientation of cell divisions in the closing Xenopus neural tube: metaphase plates rotate rapidly approximately 1.5 min before anaphase with an angular speed of approximately $60^{\circ}$ per min (Kieserman and Wallingford, 2009). Rapid rotations can also be observed in the pregastrulation embryonic disc of the rabbit (Fig. 7A-L) but they occurred within a larger time window (an 8-min period) before anaphase and were somewhat slower (up to $45^{\circ}$ per min). As most metaphase plates were already oriented parallel to the A-P axis before the 8- min time window, these late and rapid rotations may be seen as "corrective" movements. However, the functional significance of these sudden rotations and of the slight oscillations (s. Supp. Movie S5), for that matter, remains to be determined by future studies which would also analyze the fate of cells that arise from rapidly rotating metaphase plates.

\section{Conclusions}

The live recordings of this study suggest that both oriented cell division and a dedicated type of cell movement (here referred to as processional cell movement or PCM) act in concert to form the early mammalian primitive streak by cell accumulation with minimal anteroposterior elongation. However, analysis of planar cell behavior still needs to be extended to the whole embryonic disc and throughout the entire period of primitive streak formation to record a higher proportion of complete PCM and to take specific cell behavior (e.g., tandem movements, V.H., unpublished observations) prior and following PCM into account. Similar recordings may also be carried out in other mammalian model organisms in which axial differentiation is apparent in a planar embryonic disc before primitive streak formation, such as in the tammar wallaby (Hickford et al., 2008). This may then also reveal a possible functional correlation between PCM and oriented cell division during primitive streak formation. Determining the fate of oriented cell divisions and of processional cells and the molecular mechanisms causing their accompanying cellular deformation (cf. Lecuit and Lenne, 2007; Krieg et al., 2008; Mammoto and Ingber, 2010) may lead an informed assessment as to whether PCM or oriented cell division is the major factor for creating the cell density of the mammalian primitive streak. However, this study already suggests that analyzing cell proliferation and cell movement simultaneously during mammalian gastrulation may establish new regulatory mechanisms, or may indicate how molecular factors act at the cellular level to control axial differentiation in the mammalian embryo 
(cf. Arnold and Robertson, 2009). In addition, questions can now be asked as to where and when axial information is generated in species with a mammotypical flat embryonic disc and how these factors control complex individual cell behavior leading to the overt, irreversible axial differentiation during gastrulation.

\section{EXPERIMENTAL PROCEDURES}

\section{Rabbit Blastocysts}

Naturally mated New Zealand White rabbits (Lammers, Euskirchen, Germany) were superovulated by single injections of pregnant mare serum gonadotropin (100 IE intramuscularly; Intergonan, Intervet, Unterschleißheim, Germany) and human choriogonadotropin (180 IE intramuscularly; Predalon, Organon, Oberschleißheim, Germany) $72 \mathrm{hr}$ in advance and immediately before mating, respectively. Animals were killed by means of administration of an overdose (320 mg) of Narcoren (Merial, Hallbergmoos, Germany) intravenously. At 6.2 days postcoitum (dpc) blastocysts were flushed from uteri using warm $\left(37^{\circ} \mathrm{C}\right)$ phosphate buffered saline (PBS) and then washed in warm PBS twice to remove blood and tissue residue. Blastocysts were then transferred to warm HAM's F10 culture medium (Biochrom AG, Berlin, Germany), supplemented with $20 \%$ fetal calf serum, 50 IU penicillin and $50 \mu \mathrm{g} / \mathrm{ml}$ streptomycin (both Biochrom, Berlin) and kept in an incubator at $37^{\circ} \mathrm{C}$ under $5 \% \mathrm{CO}_{2}$ until used for time-lapsing microscopy (see below). After recording, blastocysts were cultivated at the same conditions up to 18 $\mathrm{hr}$ to reach the next stage of development (stage 3 ) and only those that had developed to the stage of gastrulation were taken for this study. Embryos were staged before, and upon completion of, time-lapse recording as well as at the end of the culture period using dark field optics (Leica MZ 16 Stereomicroscope, Leica Microsystems, Wetzlar, Germany). Dark field photographs were taken using a SPOT Insight wide-field $4 \mathrm{MP}$ CCD color digital camera (Visitron Systems GmbH, Puchheim, Germany).

\section{Time-Lapse Recording Using Multiphoton Microscopy}

Intact blastocysts $(6.2 \mathrm{dpc})$ were injected with the lipophilic carbocyanine DiI dissolved in germ oil using the CellTram vario system (Eppendorf, Hamburg, Germany). The microinjection of an oil bead between the zona pellucida and the embryonic disc was used as a marker to find the optimal orientation of the blastocyst on the stage of the confocal laser microscope and to verify that the embryo does not move as a whole during a recording session. Microinjection was carried out using a borosilicate glass capillary micropipette (1.0 mm O.D. $\times$ $0.78 \mathrm{~mm}$ ID, HARVARD apparatus) pulled in a Flaming/Brown Micropipette Puller (Model P-97, Sutter Instrument Co., Science Products $\mathrm{GmbH}$, Hofheim, Germany). The blastocysts with the oil mark were photographed before and after time-lapse recording with a semi-dark field illumination (Stemi SV 11, Zeiss, Germany). After injection, blastocysts were stained with the vital DNA dye DAPI (Sigma, Muenchen, Germany) at a concentration of $1 \mu \mathrm{g} / \mathrm{ml}$ in equilibrated Ham's F10 medium for $1 \mathrm{hr}$ at $37^{\circ} \mathrm{C}$ and $5 \% \quad \mathrm{CO}_{2}$ (Reupke et al., 2009). Injected and stained blastocysts were positioned in a glass bottom dish in such a way that the embryonic disc faced the glass bottom and the region of interest of the disc lay in the center of the microscope lens. To avoid displacement, the blastocyst was placed on a metal ring with a diameter slightly smaller than the diameter of the blastocyst and the dish was filled with Ham's F10 medium to a level just below the abembryonic pole of the blastocyst. This was carried out immediately before the start of recording in a chamber mounted onto an inverse True Confocal Scanner Leica TCS SP2 microscope (Leica Microsystems, Wetzlar, Germany). Using the multiphoton effect of a tunable Ti:Sapphire Chameleon laser (Coherent, Dieburg, Germany) controlled by an electro-optic modulator (LINOS Photonics $\mathrm{GmbH}$ \& Co. KG, Göttingen, Germany), stained blastocysts were visualized. One image as the average of three single scans was recorded every 5 min. Recordings were limited to a maximum of $2 \mathrm{hr}$ because blastocyst expansion lead to tissue movement in the vertical plane and this gradually moved the embryonic disc out of the working range of lens during the time of the time-lapse recording; to follow individual cells while they were moved co-axially by this general blastocyst expansion, pictures were taken at every time point in four to six optical focal planes at intervals of $10 \mu \mathrm{m}$, depending on the size, thickness and co-axial position of the embryonic disc. To assure the position and overall morphology of the embryonic disc at the beginning and at the end of each time-lapse recording single transmission contrast images were taken using an Ar-laser. Tracking of cell movement was carried out in eight embryos using a $\times 20$ lens and, therefore, in an area measuring 350 $\times 250 \mu \mathrm{m}$, which corresponds roughly to the size of the PGE area.

\section{Time-Lapse Recording Using Differential Interference Contrast (DIC)}

Images were acquired at an interval of 40 sec using an Axiovert 200M microscope equipped with an Axiocam MRm camera (both Zeiss, Jena, Germany) by means of Nomarski contrast and the AxioVison software. If required, image acquisition was briefly interrupted to assure optimal positioning of the area of interest in the depth of the focal plane; this lead to image sequences of variable length. Analysis with the DIC optics was carried out in 10 embryos using a $\times 40$ lens with an observation of segment of $62 \times 47 \mu \mathrm{m}$ corresponding to approximately one quarter of the PGE area.

\section{Image Analysis}

Every single stack of images was projected onto a single plane using Leica Confocal Software to obtain a twodimensional (2D) projection image from the 3D image stack along the orthogonal axis. Then, the projection images were assembled using ImageJ software (Wayne Rasband, National Institutes of Health, USA, http:// rsbweb.nih.gov/ij/) and a movie was made from all projected images (Abramoff et al., 2004). Individual cell nuclei were tracked using plug-in 
MTrackJ. For each mitotic cell of the DAPI time-lapse movies, the orientation of the metaphase plates was marked with a line in the last image before the anaphase. In the DIC movies the orientation of the metaphase plates was indicated at every time point of the recording using ImageJ. The angles between the metaphase plate and the A-P axis were determined in such a way that $0^{\circ}$ resp. $180^{\circ}$ designates parallel lines to the A-P axis. Positive values describe a counter-clockwise deviation from the A-P axis. Because the lines determining the orientation of the metaphase plates have no distinguishable ends, angles differing by $180^{\circ}$ were considered to be identical.

\section{Statistical Analysis}

For the circular variance as well as for the assessment of its significance level against uniform distribution, the Rao test for homogeneity of angular data (Rao, 1967) was applied. Computation was done using the $R$ port of the package CircStats (Berens, 2009). For this purpose, all angles were multiplied by two to obtain data in the full circle range $\left[-180^{\circ}, 180^{\circ}\right]$. Circular variance and mean value, also called dispersion and polar vector, were calculated from these data. The mean value was subsequently multiplied by 0.5 . The homogeneity tests were cross-checked by MonteCarlo simulation. To obtain an intuitive picture of the order of magnitude of variation among angles, data were mapped to the interval $\left[-90^{\circ}, 90^{\circ}\right]$ and the standard deviation of these linearized data was computed.

\section{ACKNOWLEDGMENTS}

The excellent technical assistance of Kirsten Falk-Stietenroth and Irmgard Wei $\beta$ is gratefully acknowledged. We also thank Hans-Georg Sydow for his unfailing help with image processing.

\section{REFERENCES}

Abramoff MD, Magelhaes PJ, Ram SJ. 2004. Image processing with ImageJ. Biophoton Int 11:36-42.

Arboleda-Estudillo Y, Krieg M, Stuhmer J, Licata NA, Muller DJ, Heisenberg CP. 2010. Movement directionality in collective migration of germ layer progenitors. Curr Biol 20:161-169.
Arnold SJ, Robertson EJ. 2009. Making a commitment: cell lineage allocation and axis patterning in the early mouse embryo. Nat Rev Mol Cell Biol 10: 91-103.

Berens P. 2009. CircStat: a MATLAB toolbox for circular statistics. J Stat Softw. 31:10.

Bertet C, Sulak L, Lecuit T. 2004. Myosin-dependent junction remodelling controls planar cell intercalation and axis elongation. Nature 429:667-671.

Bodenstein L, Stern CD. 2005. Formation of the chick primitive streak as studied in computer simulations. J Theor Biol 233:253-269.

Burtscher I, Lickert H. 2009. Foxa2 regulates polarity and epithelialization in the endoderm germ layer of the mouse embryo. Development 136:1029-1038.

Callebaut M, Van Nueten E. 1994. Rauber's (Koller's) sickle: the early gastrulation organizer of the avian blastoderm. Eur J Morphol 32:35-48.

Caneparo L, Huang YL, Staudt N, Tada M, Ahrendt R, Kazanskaya O, Niehrs C, Houart C. 2007. Dickkopf-1 regulates gastrulation movements by coordinated modulation of Wnt/beta catenin and Wnt/PCP activities, through interaction with the Dally-like homolog Knypek. Genes Dev 21:465-480.

Concha ML, Adams RJ. 1998. Oriented cell divisions and cellular morphogenesis in the zebrafish gastrula and neurula: a time-lapse analysis. Development 125:983-994.

Contreras EG, Gaete M, Sanchez N, Carrasco H, Larrain J. 2009. Early requirement of Hyaluronan for tail regeneration in Xenopus tadpoles. Development 136:2987-2996.

Coolen M, Nicolle D, Plouhinec JL, Gombault A, Sauka-Spengler T, Menuet A, Pieau C, Mazan S. 2008. Molecular characterization of the gastrula in the turtle Emys orbicularis: an evolutionary perspective on gastrulation. PLoS One 3:e2676.

Cui C, Yang X, Chuai M, Glazier JA, Weijer CJ. 2005. Analysis of tissue flow patterns during primitive streak formation in the chick embryo. Dev Biol 284: $37-47$.

Downs KM, Davies T. 1993. Staging of gastrulating mouse embryos by morphological landmarks in the dissecting microscope. Development 118:1255-1266.

Eakin GS, Behringer RR. 2004. Diversity of germ layer and axis formation among mammals. Semin Cell Dev Biol 15:619-629.

Fischer E, Legue E, Doyen A, Nato F, Nicolas JF, Torres V, Yaniv M, Pontoglio M. 2006. Defective planar cell polarity in polycystic kidney disease. Nat Genet 38:21-23.

Gilland EH, Burke AC. 2004. Gastrulation in reptiles. In: Stern C, editor. Gastrulation: from cells to embryo. New York: Cold Spring Harbor. p 205-217.

Gong Y, Mo C, Fraser SE. 2004. Planar cell polarity signalling controls cell division orientation during zebrafish gastrulation. Nature 430:689-693.
Gräper L. 1929. Die Primitiventwicklung des Hühnchens nach stereokinematographischen Untersuchungen, kontrolliert durch vitale Farbmarkierung und verglichen mit der Entwicklung anderer Wirbeltiere. Arch Entwickl Mech Org : 382-429.

Hassoun R, Schwartz P, Feistel K, Blum M, Viebahn C. 2009. Axial differentiation and early gastrulation stages of the pig embryo. Differentiation 78:301-311.

Hickford D, Shaw G, Renfree MB. 2008. In vitro culture of peri-gastrulation embryos of a macropodid marsupial. J Anat 212:180-191.

Idkowiak J, Weisheit G, Plitzner J, Viebahn C. 2004. Hypoblast controls mesoderm generation and axial patterning in the gastrulating rabbit embryo. Dev Genes Evol 214:591-605.

Keller R. 2002. Shaping the vertebrate body plan by polarized embryonic cell movements. Science 298:1950-1954.

Kieserman EK, Wallingford JB. 2009. In vivo imaging reveals a role for Cdc42 in spindle positioning and planar orientation of cell divisions during vertebrate neural tube closure. J Cell Sci 122:2481-2490.

Koller C. 1882. Untersuchungen über die Blätterbildung im Hühnerkeim. Arch Mikrosk Anat :174-211.

Krieg M, Arboleda-Estudillo Y, Puech PH, Käfer J, Graner F, Müller DJ, Heisenberg CP. 2008. Tensile forces govern germ-layer organization in zebrafish. Nat Cell Biol 10:429-436.

Kwon GS, Viotti M, Hadjantonakis AK. 2008. The endoderm of the mouse embryo arises by dynamic widespread intercalation of embryonic and extraembryonic lineages. Dev Cell 15:509-520.

Lawson KA, Meneses JJ, Pedersen RA. 1991. Clonal analysis of epiblast fate during germ layer formation in the mouse embryo. Development 113: 891-911.

Lecuit T, Lenne P. 2007. Cell surface mechanics and the control of cell shape, tissue patterns and morphogenesis. Nature Rev Mol Cell Biol 8:633-644.

Luckett WP. 1978. Origin and differentiation of the yolk sac and extraembryonic mesoderm in presomite human and rhesus monkey embryos. Am J Anat 152: 59-97.

Mammoto T, Ingber DE. 2010. Mechanical control of tissue and organ development. Development 137:1407-1420.

Montero JA, Carvalho L, Wilsch-Brauninger M, Kilian B, Mustafa C, Heisenberg CP. 2005. Shield formation at the onset of zebrafish gastrulation. Development 132:1187-1198.

Nakatsuji N, Snow MHL, Wylie CC. 1986. Cinemicrographic study of the cell movement in the primitive-streak-stage mouse embryo. J Embryol Exp Morphol 96:99-109.

O'Connell CB, Wang YL. 2000. Mammalian spindle orientation and position respond to changes in cell shape in a dynein-dependent fashion. Mol Biol Cell 11:1765-1774. 
Olivier N, Luengo-Oroz MA, Duloquin L, Faure E, Savy T, Veilleux I, Solinas X, Debarre D, Bourgine P, Santos A, Peyrieras N, Beaurepaire E. 2010. Cell lineage reconstruction of early zebrafish embryos using label-free nonlinear microscopy. Science 329:967-971.

Perea-Gomez A, Lawson KA, Rhinn M, Zakin L, Brulet P, Mazan S, Ang SL. 2001. Otx2 is required for visceral endoderm movement and for the restriction of posterior signals in the epiblast of the mouse embryo. Development 128: 753-765.

Rao CR. 1967. Least squares theory using an estimated dispersion matrix and its application to measurement of signals. Proceedings of the Fifth Berkeley Symposium on Mathematical Statistics and Probability, Volume 1: Statistics. Berkeley: University of California Press. p 355-372.

Reupke T, Püschel B, Viebahn C. 2009. Tracing and ablation of single cells in the mammalian blastocyst using fluorescent DNA staining and multiphoton laser. Histochem Cell Biol 131:521-530.

Sanders EJ, Varedi M, French AS. 1993. Cell proliferation in the gastrulating chick embryo: a study using BrdU incorporation and PCNA localization. Development 118:389-399.

Sausedo RA, Schoenwolf GC. 1993. Cell behaviors underlying notochord formation and extension in avian embryos: quantitative and immunocytochemical studies. Anat Rec 237:58-70.

Sausedo RA, Smith JL, Schoenwolf GC. 1997. Role of nonrandomly oriented cell division in shaping and bending of the neural plate. J Comp Neurol 381:473-488.

Shimizu H, Bode PM, Bode HR. 1995. Patterns of oriented cell division during the steady-state morphogenesis of the body column in hydra. Dev Dyn 204 349-357.

Srinivas S, Rodriguez T, Clements M, Smith JC, Beddington RS. 2004. Active cell migration drives the unilateral movements of the anterior visceral endoderm. Development 131:1157-1164.

Stern CD. 1990. The marginal zone and its contribution to the hypoblast and primitive streak of the chick embryo. Development 109:667-682.

Strutt D. 2005. Organ shape: controlling oriented cell division. Curr Biol 15: R758-R759.

Suriben R. 2009. Posterior malformations in Dact1 mutant mice arise through misregulated Vangl2 at the primitive streak. Nat Genet 41:977-985.

Tam PPL, Gad JM. 2004. Gastrulation in the mouse embryo. In: Stern C, editor. Gastrulation: from cells to embryo. New York: Cold Spring Harbor. p 233-262.

Ulrich F, Concha ML, Heid PJ, Voss E, Witzel S, Roehl H, Tada M, Wilson SW, Adams RJ, Soll DR, Heisenberg CP. 2003. Slb/Wnt11 controls hypoblast cell migration and morphogenesis at the onset of zebrafish gastrulation. Development 130:5375-5384.

Ulrich F, Krieg M, Schotz EM, Link V, Castanon I, Schnabel V, Taubenberger A, Mueller D, Puech PH, Heisenberg CP. 2005. Wnt11 functions in gastrulation by controlling cell cohesion through Rab5c and E-cadherin. Dev Cell 9:555-564.

Viebahn C. 1999. The anterior margin of the mammalian gastrula: comparative and phylogenetic aspects of its role in axis formation and head induction. Curr Top Dev Biol 46:63-103.

Viebahn C, Mayer B, Hrabe de Angelis M. 1995. Signs of the principal body axes prior to primitive streak formation in the rabbit embryo. Anat Embryol (Berl) 192:159-169.

Viebahn C, Stortz C, Mitchell SA, Blum M. 2002. Low proliferative and high migratory activity in the area of Brachyury expressing mesoderm progenitor cells in the gastrulating rabbit embryo. Development 129:2355-2365.
Vogt W. 1925. Gestaltungsanalyse am Amphibienkeim mit örtlicher Vitalfärbung. I. Teil. Methodik und Wirkungsweise der örtlichen Vitalfärbung mit Agar als Farbträger. Rou's Archiv Entwickl Mech :542-610.

Voiculescu O, Bertocchini F, Wolpert L, Keller RE, Stern CD. 2007. The amniote primitive streak is defined by epithelial cell intercalation before gastrulation. Nature 449:1049-1052.

Wei Y, Mikawa T. 2000. Formation of the avian primitive streak from spatially restricted blastoderm: evidence for polarized cell division in the elongating streak. Development 127:87-96.

Wetzel R. 1929. Untersuchungen am Hühnchen. Die Entwicklung des Keims während der ersten beiden Bruttage. Arch Entwickl Mech Org : 188-321.

Wyngaarden LA, Vogeli KM, Ciruna BG, Wells M, Hadjantonakis AK, Hopyan S. 2010. Oriented cell motility and division underlie early limb bud morphogenesis. Development 137:2551-2558.

Yamanaka Y, Tamplin OJ, Beckers A, Gossler A, Rossant J. 2007. Live imaging and genetic analysis of mouse notochord formation reveals regional morphogenetic mechanisms. Dev Cell 13:884-896.

Yen WW, Williams M, Periasamy A, Conaway M, Burdsal C, Keller R, Lu X, Sutherland A. 2009. PTK7 is essential for polarized cell motility and convergent extension during mouse gastrulation. Development 136:2039-2048.

Zallen JA. 2007. Planar polarity and tissue morphogenesis. Cell 129:1051- 1063.

Zallen JA, Blankenship J. 2008. Multicellular dynamics during epithelial elongation. Sem Cell Dev Biol 19:263- 270.

Zhang Y, Levin M. 2009. Left-right asymmetry in the chick embryo requires core planar cell polarity protein Vangl2. Genesis 47:719-728. 


\subsection{Manuscript to Be Submitted 'Tracing Ancestral Gastrulation through Modified Cellular Movements in the Mammalian Embryo'}

Viktoria Stankova $^{1^{*}}$, Nikoloz Tsikolia ${ }^{1}$, Christoph Viebahn ${ }^{1}$

${ }^{1}$ Department of Anatomy and Embryology, Centre of Anatomy, University of Göttingen, Germany

${ }^{*}$ Viktoria Stankova, née Halacheva

Author contributions:

V.S. designed and carried out the experiments and prepared the figures; N.T. carried out the electron microscopical analysis; V.S., N.T. and C.V. analyzed the data and wrote the manuscript. 


\title{
Title: Tracing ancestral gastrulation through modified cellular movements in the mammalian embryo
}

Authors: Viktoria Stankova ${ }^{1}$, Nikoloz Tsikolia ${ }^{1}$, Christoph Viebahn ${ }^{1}$

\begin{abstract}
Affiliation:
${ }^{1}$ Department of Anatomy and Embryology, University of Göttingen, 37079 Göttingen, Germany.

*Correspondence to: christoph.viebahn@medizin.uni-goettingen.de
\end{abstract}

\begin{abstract}
Animal gastrulation specifies the embryonic axes and induces the first major change in cell shape after fertilisation. The 'milieu intérieur' is thus created in disparate topographical arrangements such as the circular blastopore of amphibia or the straight primitive streak of amniotes (birds and mammals). We modified mammalian gastrulation topography by interfering selectively with pre-gastrulation planar cell movements using rabbit blastocyst cultures. Time-lapse videomicroscopy, ultrastructural analysis and gene expression after Rho kinase inhibition show a dose-dependent molding of the prospective primitive streak into regularly patterned circular or arch-like forms, as known in amphibia, fish or reptiles. The mammalian embryo reveals that temporal shift and consecutive adjustment of planar cell movements can be instrumental to the evolution of gastrulation forms.
\end{abstract}


Main text: The straight primitive streak in avian or mammalian embryonic discs and the circular ancestral blastopore in amphibia have long been the favored analogues in the evolution of early vertebrate development $(1,2)$. As central elements of the so-called gastrulation process, they fix the coordinates of the three principal embryonic axes and starting on the future dorsal side - induce the first major change in cell shape post fertilisation, termed epithelio-mesenchymal transition (EMT) (3). The basis is thereby created for the 'milieu intérieur' and all internal organs. Extant reptilian embryos phylogenetically basal to birds and mammals have both a small blastopore analogue and a primitive plate, indicating that the primitive streak could have emerged twice during the course of evolution of amniote gastrulation (4). However, we suggest that directed cell movements toward the embryonic shield in zebrafish (5), and complex cell rearrangements forming the primitive streak in birds (6) and mammals (7), may be possible cellular mechanisms for the evolution of the amphibian blastopore (8). With these hypotheses in mind, we set out to find direct evidence of cellular activity that may account for the transition from one topographical arrangement into the other.

Time-lapse laser microscopy recently revealed the essential characteristics of directed intraepithelial cell movements forming the primitive streak in the chick (6): several components of the planar cell polarity (PCP) pathway (9), also operating at later stages in the gastrulating frog Xenopus and fish Danio rerio (zebrafish) (10, 11), ensure that concerted mediolateral cell intercalation in the epiblast leads to the first midline structure in a flat embryonic disc. The intercalating cell movements forming the 'polonaise' described in the posterior area of chick embryonic disc (6) can also be observed in a living mammalian embryo when the rabbit embryo with its flat embryonic disc on the preimplantation blastocyst surface is analysed using multiphoton laser microscopy (7). Moreover, a new type of (intercalating) 'processional cell movement' was found in the rabbit which appears to meet the high migratory speed demands during the drastic increase in size of the mammalian embryo at the start of gastrulation (7). Now, again using the rabbit and essentially the same optical set up (fig. S1) but extended filming times (12), these cell movement patterns were complemented by the discovery of inverted L- and Uturns near and within the primtive streak (Fig. 1A-E, video S1-2), which we interpret to be necessary for primitive streak elongation once it is formed. 
With this set of cell movement types at hand we asked the question as to how planar cell movements might contribute to the dynamics of the mammalian primitive streak and its differentiation into dorsal vs. ventral mesoderm. We interfered chemically with a Rho kinase (ROCK), which was shown before to be causally involved - via the actomyosin cytoskeleton - in the leading edge of migrating cells (13), in gastrulation-type EMT (14) and in PCP-controlled cell movements during gastrulation in Xenopus (15). As expected, polonaise movements (and the actin cytoskeleton: fig. S2) were disturbed specifically in the posterior gastrula extension (PGE), the future primitive streak forming area of the embryonic disc (Fig. 1F-J, video S3). instead of L- and U-turns centrifugal cell movements prevailed and lead to a concentric widening of the PGE; this widening was supported by epiblast cells in the (anterolateral) part of the embryo which either were redirected to turn posteriorly (close to the PGE, cf. Fig. 1E and J) or - in the anterior half of the embryonic disc - behaved normally, e.g. proliferated and thereby caused increased epithelial thickness (16) (Fig. 2E). In the mouse, the only other mammalian embryo analysed for live cell movement during primitive streak formation so far, only occasional L- and U-turns were observed amongst the physiological PCP-dependent cell movements $(17,18)$; this discrepancy between mouse and rabbit may be explained by topographical constraints at the rim of the rodent cup-shaped 'egg cylinder' which make local cell proliferation sufficient to contribute the main bulk to the primitive streak cell density at the (posterior) part of the egg cylinder.

Intriguingly, our ROCK inhibitor experiments caused different grades of primitive streak deformation in a dose-dependent manner. This was seen after analysis of Brachyury expression (Fig. 2A-E), one of the master genes of mesoderm formation (19): Low doses of ROCK inhibitor produce a widened, but still densely Brachyury-expressing primitive streak area (Fig. 2B) similar to that seen in the chick after interfering with the dishevelled component of PCP (6); at higher inhibitor concentrations, in contrast, circular 'blastoporelike' Brachyury-negative areas of different diameters appeared in the center of the primitive streak forming area at a high percentage (50/87, cf. table S1) even when a small or middlesized primitive streak was present already at the start of culture (12/14 or 5/8, respectively; cf. table S2). These artificial 'blastopores' were flanked bilaterally by triangular Brachyuryexpressing domains (Fig. 2C-E) which were classified to represent three grades of widened 
gastrulation centers (WGC, table S2). The use of even higher inhibitor concentrations resulted in either collapse of the blastocyst due to extreme thinning of the PGE area (2/6) or in maximally widened gastrulation centers in which the two flanking Brachyury-expressing domains formed an arch-like equatorial shape scarcely connected by the node region in the midline (4/6; Fig. 2F). These abnormal Brachyury expression patterns appear to mirror the expression domains in gastrulation centers in amphibia (20) (blastopore, cf. Fig. 2C), reptiles $(4,21)$ and teleost fish (22) (embryonic shield, cf. Fig. 2 E) and they are indeed comparable to putative transient gastrulation forms during evolution from ancestral amphibia to amniotes (8).

High-resolution histology of experimental Brachyury-expressing embryonic discs (Fig. 2G-J) showed that the band representing the primitive streak and the EMT area occupying the posterior midline (23), was replaced by a thin two-layered Brachyurynegative region (Fig. 2I and J). We therefore asked (1) whether EMT, and preceding breakdown of the epiblast basement membrane, both of which appear to be dependent on ROCK activity $(14,24)$, could be found in these experimental embryos and (2) whether this is associated with the widened gastrulation centers (cf. (25)). Indeed, transmission electron microscopy of treated embryos revealed a thin and interrupted basement membrane in the anterior half of the embryo, while it was completely absent in the posterior gastrula extension (PGE) area (fig. S3A, C-E). Ingression of mesoderm indicative of EMT was confined to ectopic areas lying lateral to the midline. Specifically, lateral Brachyury expression domains in which the transition of Brachyury positive to negative epiblast define the lateral border of EMT to be the so-called epithelio-mesenchymal hinge (EMH, Fig. 3 and fig. S3A, B). Moreover, EMT is observed in isolated patches near the embryonic disc border (Fig. 2G) indicating that EMT areas correlate with the distribution of Brachyury expression domains (Fig. 2B-F). Our ultrastructural analysis supports the view that EMT may occur indeed independently of structural integrity of the primitive streak (25) and by successive initiation, as in the mouse (17). Importantly, this EMT pattern with a single EMH on the lateral border of EMT areas only excludes the possibility of a simple axis duplication and makes the different gastrulation forms artificially obtained in the rabbit a likely representation of the evolutionary path from ancestral amphibia to birds and mammals (8). Dorso-ventral patterning, however, is not disturbed as seen by the ongoing 
development of the organizer region which expresses - in addition to Brachyury - the notochord marker Chordin (26) (fig. S4) and displays the typical arrangement of prospective neuroectoderm and notochord at the tip of the experimental primitive streaks (Fig. 2B-F and I').

To find evidence of ROCK inhibition acting specifically through PCP signalling, inhibition experiments with Latrunculin A (LatA) were carried out, which globally impairs the actin cytoskeleton and thus cellular activities such as intracellular transport, cytokinesis and cell movement (Fig. 4): Small undirected, oscillating movements of epiblast cells were observed throughout the whole embryonic disc (movie S4) and were accompanied by incomplete cytokinesis, abnormal intracellular accumulation of actin in the whole epiblast, and by hypoblast rhexis and constriction in all areas of the embryonic disc (fig. S5; cf. fig. S2). Brachyury expression showed a general widening of the primitive streak and expansion of weak expression up to the tip of the primitive streak, but there was no expression in the area of the prospective node as in the ROCK inhibited embryos (cf. fig. S5C and Fig. 2B-F). The LatA experiments thus highlight the specific effect of ROCK inhibition on PCP-dependent directed cell movements in the posterior half of the embryonic disc where the primitive streak but not the node (as the representative of dorsal mesoderm) is formed. Indeed, preserved Brachyury and Chordin expression and notochord formation in the future node region of ROCK inhibited embryos with a maximally widened primitive streak (Fig. 2B-E, I) also emphasises the Brachyury-negative anterior half of the normal primitive streak where EMT appears to start independently of the mesoderm 'master' gene (cf. (25)). This we intepret to indicate a physiological anterior-posterior polarity of the artificial gastrulation centers known from normal amniote primitive streaks (16), which would lead to normal dorso-ventral tissue fates if gastrulation were allowed to proceed despite the abnormal shape.

From the evolutionary perspective our results provide evidence of cellular mechanisms for scenarios which explain - on the basis of an increasing yolk mass (8) and a temporal shift of cellular mechanisms (27) - how the 'primitive' ancestral blastopore could have been converted into the radially oriented primitive streak of amniotes: Limited planar cell movements - producing the extreme form of artificial primitive streak widening in the rabbit - lead to an equatorial Brachyury-expressing gastrulation center typically found in an 
ancestral gastrula $(8,22)$. Larger-scale directed planar cell movements - producing first grade artificial primitive streak widening in the rabbit - lead to reptilian-style gastrulation $(4,8,21)$. Complex cell rearrangement and extensive polonaise movements, and indeed oriented cell division $(7,28)$, represent normal amniote development and lead to the highly evolved primitive streak. Thus, the surprising similarity of the widened gastrulation center in the rabbit with the one of ancestral reptiles seems to offer the possibility that subtle adjustments of conserved planar cell motility (29) are sufficient to drive the evolution of vertebrate gastrulation. Moreover, we suggest that the independent emergence of the primitive streak in birds and mammals is based on the morphogenetic constraint (30) provided by the range of spatio-temporal modifications of PCP-directed planar cell behavior. The apparent kinship of mammalian and reptilian development and the rise of reptilian model organisms $(4,21)$ now also call for experimental analysis in reptiles to show whether cellular motility may indeed enable convergent evolution of vertebrate gastrulation centers. 


\section{References:}

1. J. Kollmann, Anat Anz 1: 281-294 (1886).

2. C. D. Stern, Cold Spring Harbor Laboratory Press, Cold Spring Harbor, NY, USA (2004).

3. J. Yang, R. A. Weinberg, Dev Cell 14: 818-829. (2008).

4. F. Bertocchini, C. Alev, Y. Nakaya, G. Sheng, Dev Growth Differ. 2013 Jan;55(1):52-9. doi: 10.1111/dgd.12014. Epub 2012 Nov 16. (2013).

5. $\quad$ R. M. Warga, C. B. Kimmel, Development 108: 569-580 (1990).

6. O. Voiculescu, F. Bertocchini, L. Wolpert, R. E. Keller, C. D. Stern, Nature. 2007 Oct 25;449(7165):1049-52. Epub 2007 Oct 10. (2007).

7. V. Halacheva, M. Dönitz, J. Fuchs, T. Reupke, B. Püschel, C. Viebahn, Dev Dyn 240: 1905-1916 (2011).

8. D. Arendt, K. Nübler-Jung, Mech Dev 81: 3-22 (1999).

9. J. R. Seifert, M. Mlodzik, Nat Rev Genet. 2007 Feb;8(2):126-38. (2007).

10. C. P. Heisenberg et al., Nature 405: 76-81 (2000).

11. J. B. Wallingford, S. E. Fraser, R. M. Harland, Dev Cell 2002 Jun;2(6):695-706. (2002).

12. Materials and methods are available as supporting material on Science Online.

13. O. Pertz, L. Hodgson, R. L. Klemke, K. M. Hahn, Nature. 2006 Apr 20;440(7087):1069-72. Epub 2006 Mar 19. (2006).

14. Y. Nakaya, E. W. Sukowati, Y. Wu, G. Sheng, Nat Cell Biol 10: 765-775 (2008).

15. E. Tahinci, K. Symes, Dev Biol. 2003 Jul 15;259(2):318-35. (2003).

16. C. Viebahn, C. Stortz, S. M. Mitchell, M. Blum, Development 129: 2355-2365 (2002).

17. M. Williams, C. Burdsal, A. Periasamy, M. Lewandoski, A. Sutherland, Dev Dyn. 2011 Dec 6. doi: 10.1002/dvdy.23711. (2011).

18. J. P. Mahaffey, J. Grego-Bessa, K. F. Liem, Jr., K. V. Anderson, Development. 2013 Mar;140(6):1262-71. doi: 10.1242/dev.085316. Epub 2013 Feb 13. (2013).

19. B. G. Herrmann, S. Labeit, A. Poustka, T. R. King, H. Lehrach, Nature 343: 617$622(1990)$. 
20. L. K. Gont, H. Steinbeisser, B. Blumberg, E. M. De Robertis, Development 119: 991-1004 (1993).

21. M. Coolen et al., PLoS One. 2008 Jul 16;3(7):e2676. (2008).

22. B. L. Martin, D. Kimelman, Dev Cell 15: 121-133 (2008).

23. C. Viebahn, B. Mayer, A. Miething, Acta Anat 154: 99-110 (1995).

24. E. Marinari et al., Nature. 2012 Apr 15;484(7395):542-5. doi: 10.1038/nature10984. (2012).

25. C. Alev, Y. Wu, Y. Nakaya, G. Sheng, Development. 2013 Jul;140(13):2691-6. doi: 10.1242/dev.094318. Epub 2013 May 22. (2013).

26. L. B. Sasai Y, Steinbeisser H, Geissert D, Gont LK, Derobertis EM,, Cell, 79 (5) p779-790 (1994).

27. M. K. Richardson, Bioessays. 1999 Jul;21(7):604-13. (1999).

28. Y. Gong, C. Mo, S. E. Fraser, Nature 430: 689-93 (2004).

29. L. Solnica-Krezel, Curr Biol. 2005 Mar 29;15(6):R213-28. (2005).

30. M. K. Richardson, A. D. Chipman, J Exp Zool B Mol Dev Evol. 2003 Apr 15;296(1):8-22. (2003).

Acknowledgements: We thank K. Falk-Stiethenrot, I. Weiß and H.-G. Sydow for technical assistance, M. Blum and R. Winklbauer for comments on earlier versions of the manuscript. This work was supported by the Deutsche Forschungsgemeinschaft (Vi151/8-1). 


\section{Legends:}

Fig. 1. Pre-gastrulation cell movements organizing the primitive streak are severely impaired by ROCK inhibition. Dorsal views of control (A-D) and experimental (F-I) rabbit embryos taken at the beginning $(\mathbf{A}, \mathbf{C}, \mathbf{F}, \mathbf{H})$ and the end $(\mathbf{B}, \mathbf{D}, \mathbf{G}, \mathbf{I})$ of the $190 \mathrm{~min}$ timelapse sequences (movies S1-3). (E, J) Paths of the traced cells (cf. C-D and H-I) relative to the posterior gastrula extension (PGE) area (anterior border marked by broken line). PS primitive streak, asterisks mark embryonic disc borders. Scale bar: A-B $250 \mu \mathrm{m}$; F-G 175 $\mu \mathrm{m} ; \mathbf{C}-\mathbf{E}, \mathbf{H}-\mathbf{J} 50 \mu \mathrm{m}$.

Fig. 2. Dose-dependent reshaping of the Brachyury expression domain by ROCK inhibition. A-F, Dorsal views of control embryo (A, cf.(25)) and embryos treated with different ROCK-inhibitor concentration (B-F) and analysed in sagittal (G-I) or transversal (J) sections. Epiblast Brachyury expression marks epithelio-mesenchymal transition (EMT, left of arrow in $\mathbf{H}^{\prime}$ ) and the epithelio-mesenchymal hinge (arrow in $\mathbf{H}^{\prime}$ ). Epiblast in the round blastopore-like reagion of a widened primitive streak (D) overlies mesoderm cells (J') but lack Brachyury expression $(\mathbf{J})$. Anterior is to the top in dorsal views (A-F) and to the left in sagittal sections (G-I). Black dots mark posterior embryonic disc borders, asterisks mark epiblast-trophoblast border. e epiblast, h hypoblast, m mesoderm. Scale bar: A-J $100 \mu \mathrm{m}$, G'-J' $50 \mu \mathrm{m}$.

Fig. 3. Schematic of progressive widening of the mammalian gastrulation center after ROCK inhibition. (A) normal primitive streak, (B) blastopore-like, (C) transitional and (D) embryonic shield-like area of epithelio-mesenchymal transition (EMT, dark blue) with epithelio-mesenchymal hinge (red dotted line) next to mesoderm cells with EMT-free epiblast (light blue). Curved arrows indicate the dorso-ventral direction of EMT and subsequent lateral mesoderm migration. n presumptive node (organizer) area. 
Fig. 4. ROCK-inhibitor (Y-27632) and latrunculin A (LatA) have differential effects on PCP-directed cell movements. Of the cytoskeleton-dependent cellular activities such as stabilization of cell shape, cell division and directed cell movements, mainly the latter is disturbed by Y-27632 whereas LatA severely affects all three. 
Figures 1-4:

\section{Figure 1}
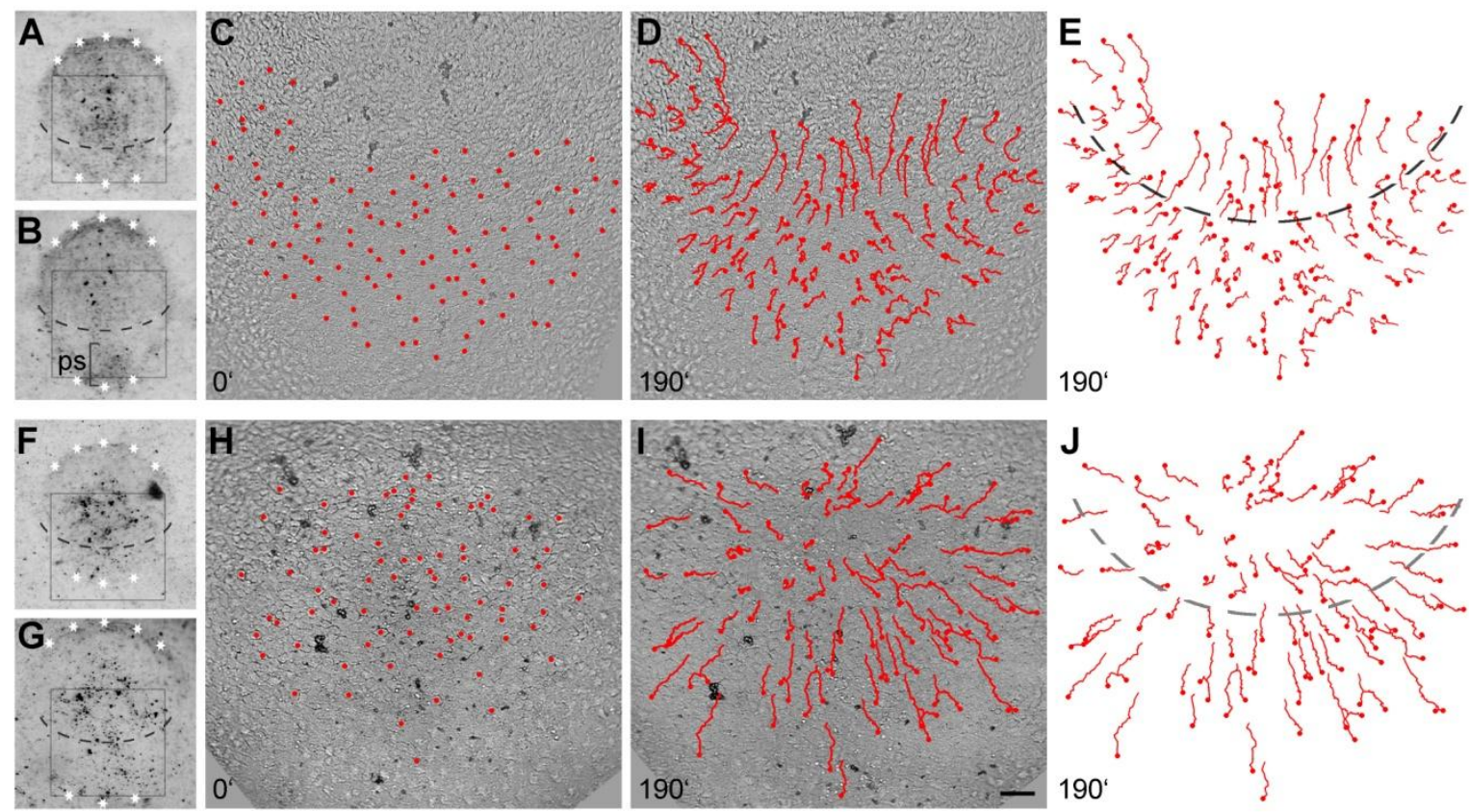

Figure 2

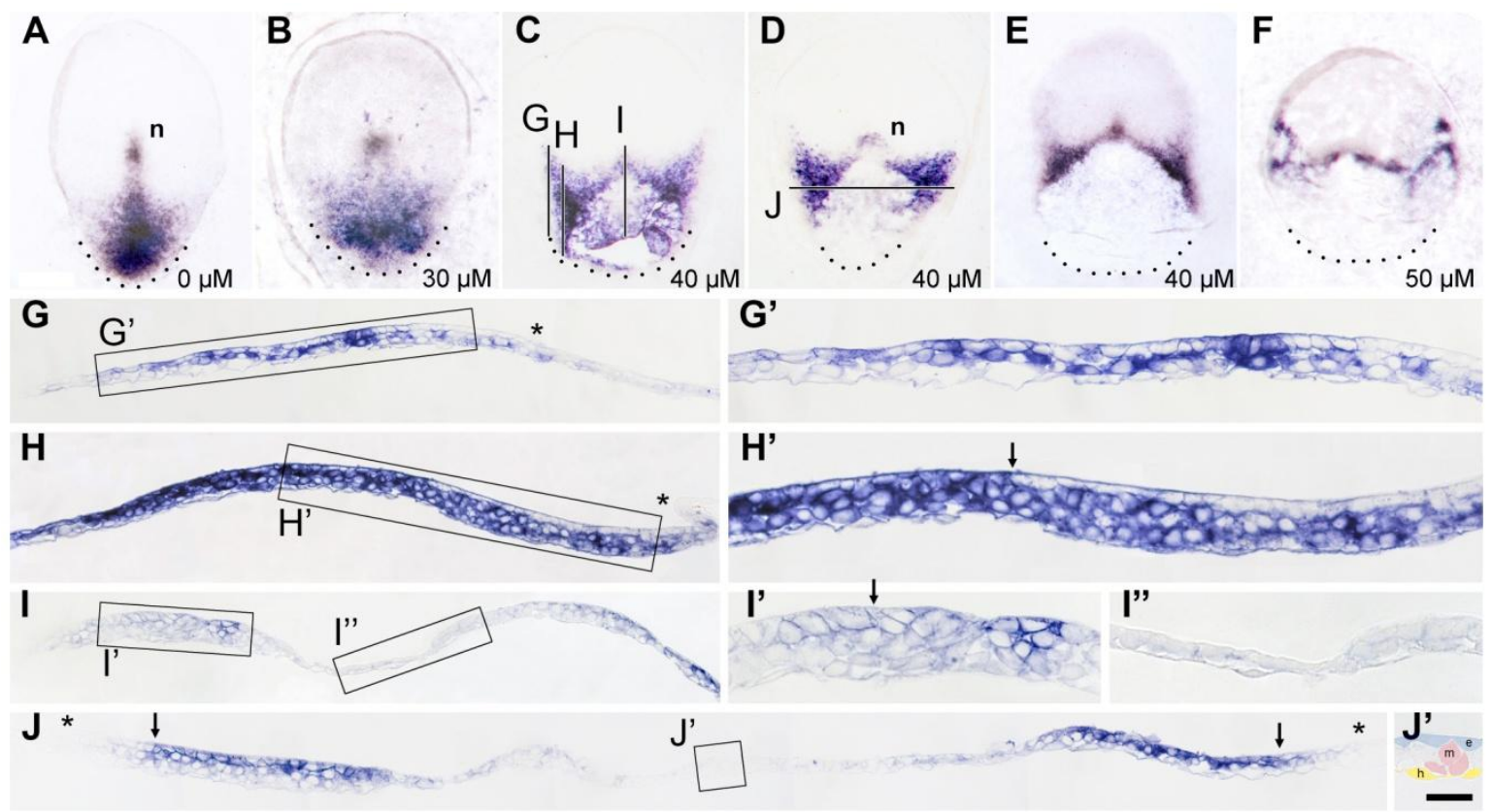




\section{Figure 3}

A

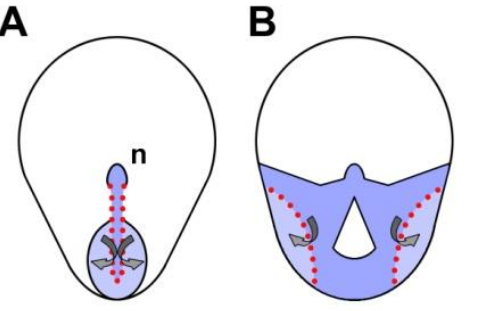

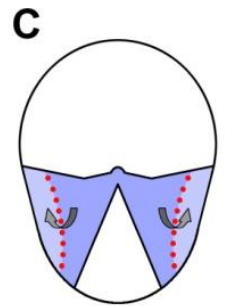

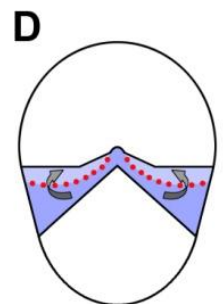

\section{Figure 4}

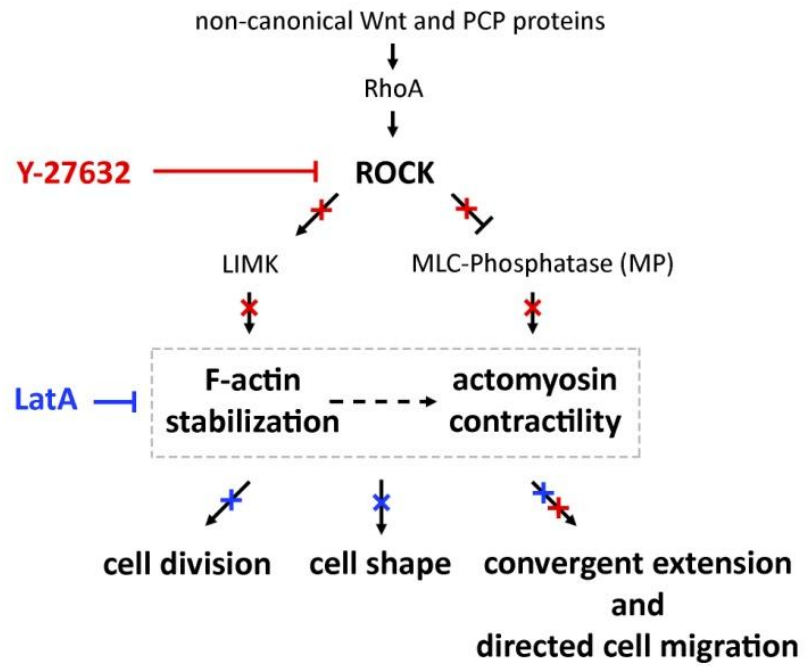




\section{Supplementary Material}

\section{Material and Methods}

\section{Embryo culture}

New Zealand white rabbit embryos were obtained as described previously (7). For blocking cell movements the inhibitory substances Y-27632 dihydrochloride (Tocris Bioscience, dissolved in phosphate buffered saline (PBS)) and latrunculin A (LatA; Sigma-Aldrich Chemie GmbH, dissolved in dimethyl sulfoxide (DMSO)) were added to HAM's F10 culture medium (Biochrom AG), supplemented with $20 \%$ fetal calf serum, 50 IU penicillin and $50 \mu \mathrm{g} / \mathrm{ml}$ streptomycin (both Biochrom AG) at the following concentrations: 20, 30, 40, 50 and $100 \mu \mathrm{mol}$ of $4 \mathrm{mmol} / \mathrm{l} \mathrm{Y}-27632$ stock and $0.5,1$ and $2.5 \mu \mathrm{mol}$ of $2.5 \mathrm{mmol} / 1$ LatA stock. Untreated control embryos were cultivated in medium with PBS or DMSO, respectively. All cultures were incubated at $37^{\circ} \mathrm{C}$ and under $5 \% \mathrm{CO}_{2}$ for $18(\mathrm{Y}-27632)$ or 6 (LatA) hours.

\section{Cloning of rabbit cDNA, In situ Hybridisation and Histology}

PCR products of rabbit cDNA corresponding to the correct size of Brachyury (16) and Chordin (Weisheit, unpublished, GenBank accession number - AY575210.1) mRNA were cloned and sequenced following standard conditions. Degenerated primer combinations were as follows: Brachyury (635 bp): 5'-CTC ACC AAC AAG CTC AAT GGA-3' (forward), 5'-GAT GGT ACC ATT GCT CAC AGA CC (reverse) and Chordin (710 bp): 5'-CAT GGT GTG GTR AAR GAY YTN GAR C-3' (forward), 5'-ACA CGS ACN GGY TGN GCR C-3' (reverse). In situ hybridisation of whole-mount rabbit embryos was carried out following standard protocols (16). Slight changes in the procedure were needed for cultured embryos, e.g. cell permeabilisation $(10 \mu \mathrm{g} / \mathrm{ml}$ proteinase $\mathrm{K}$, Roche Deutschland Holding $\mathrm{GmbH}$ ) was performed for not more than five minutes. After in situ hybridisation, $5 \mu \mathrm{m}$ transverse and sagittal sections were made from embryonic discs embedded in Technovit medium (Heraeus Kulzer GmbH). 


\section{Light and Electron Microscopy}

Embryos treated with ROCK-inhibitor were fixed in 1.5\% paraformaldehyde (PFA) and $1.5 \%$ glutaraldehyde (GA) in PBS, post-fixed in 1\% osmium oxide (OsO4) in PBS and subsequently embedded in Araldite ${ }^{\circledR}$. Serial semithin sections $(1 \mu \mathrm{m})$ of the aralditeembedded embryonic discs were made in transverse plane. For transmission electron-

microscopical study, selected semithin sections were re-embedded in $\operatorname{Araldite}^{\circledR}$ (23) and sectioned at $70 \mathrm{~nm}$.

\section{Actin Staining}

After treatment with Y-27632 and LatA whole rabbit embryonic discs were fixed with 4\% paraformaldehyde, stained with TRITC-phalloidin (dilution 1:500, Sigma) and counterstained with DAPI (dilution 1:5000, Sigma).

\section{Time-Lapse and Image Analysis}

Using differential interference contrast (DIC) cell movements of embryos treated with Y27632 or LatA were recorded with a 10x or 20x lense taking one frame every one minute for up to four hours. By means of the 10x lens the observation area corresponds to the whole embryonic disc, whereas using the 20x lens the posterior half of the embryonic disc was recorded. The time-lapse series and the following image analysis were carried out with an Axiovert 200M microscope equipped with an Axiocam MRm camera, AxioVison software (all Zeiss) and ImageJ software. Embryos were photographed at the start of the culture period as well as at the end using dark field optics (Stemi SV 11, Zeiss) and a color digital camera (SPOT Insight wide-field 4 MP CCD, Visitron Systems GmbH). 


\section{Figures S1-S5:}

\section{Figure S1}

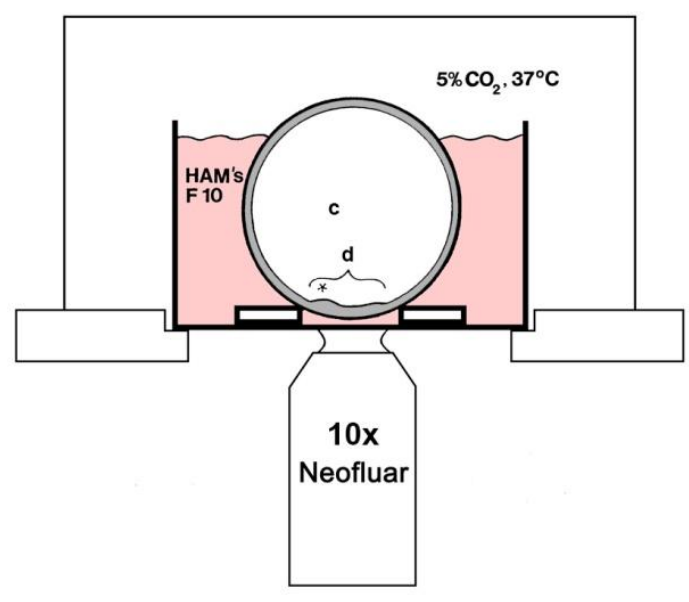

Culture set-up for time-lapse imaging of whole rabbit blastocysts. The embryonic disc (d) - integrated into the surface of the blastocyst wall - faces the glass bottom of the culture dish. Asterisk marks the anterior marginal crescent, c blastocyst cavity. 


\section{Figure S2}
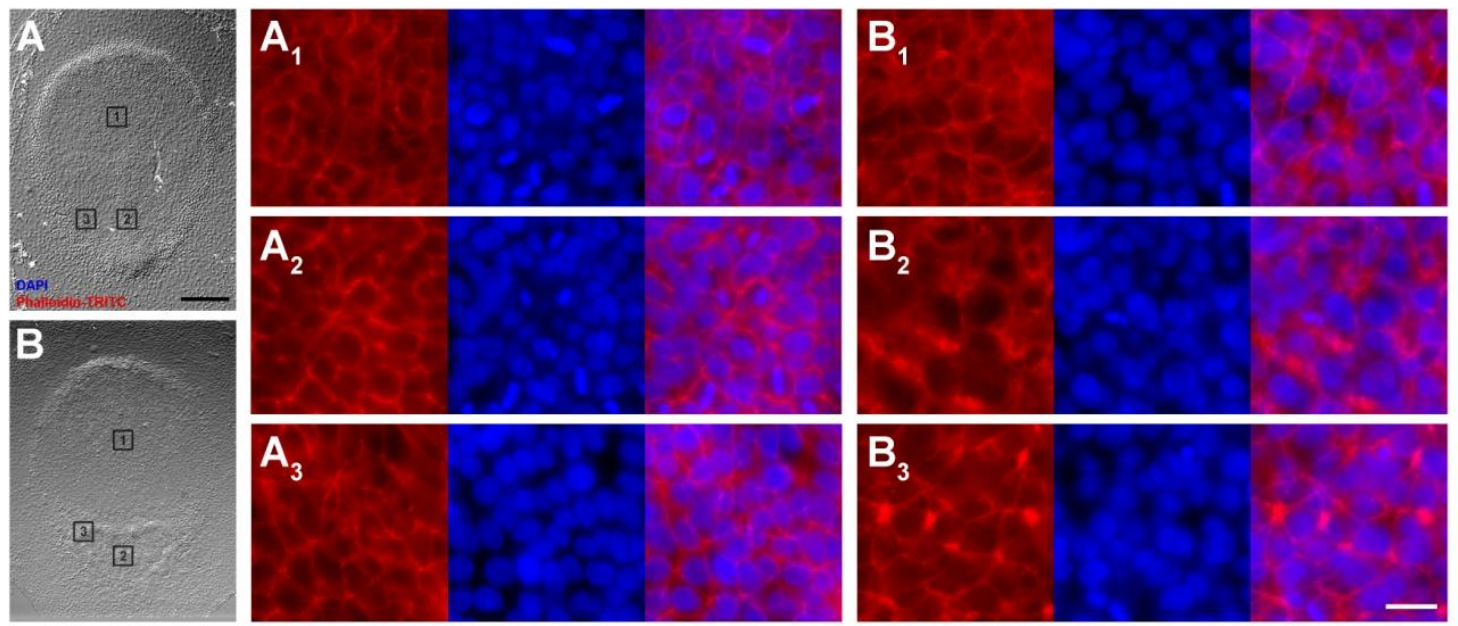

ROCK-inhibited embryos reveal abnormal intracellular actin distribution in the posterior gastrula extension (PGE) area, only. A, B, Dorsal views of control (A) and treated (B) embryo with high magnifications $\left(\mathbf{A}_{\mathbf{1}}-\mathbf{B}_{\mathbf{3}}\right)$ of phalloidin-TRITC and DAPI staining in anterior $\left(\mathbf{A}_{\mathbf{1}}, \mathbf{B}_{\mathbf{1}}\right)$ and posterior $\left(\mathbf{A}_{2,3}, \mathbf{B}_{\mathbf{2}, 3}\right)$ regions (boxed in $\mathbf{A}$ and $\left.\mathbf{B}\right)$. Clumplike actin distribution is found near the nucleus of epiblast cells in the PGE of Y-27632 treated embryos only. Scale bar: A-B $250 \mu \mathrm{m}, \mathbf{A}_{\mathbf{1}}-\mathbf{A}_{\mathbf{3}}, \mathbf{B}_{\mathbf{1}}-\mathbf{B}_{\mathbf{3}} 10 \mu \mathrm{m}$. 


\section{Figure S3}
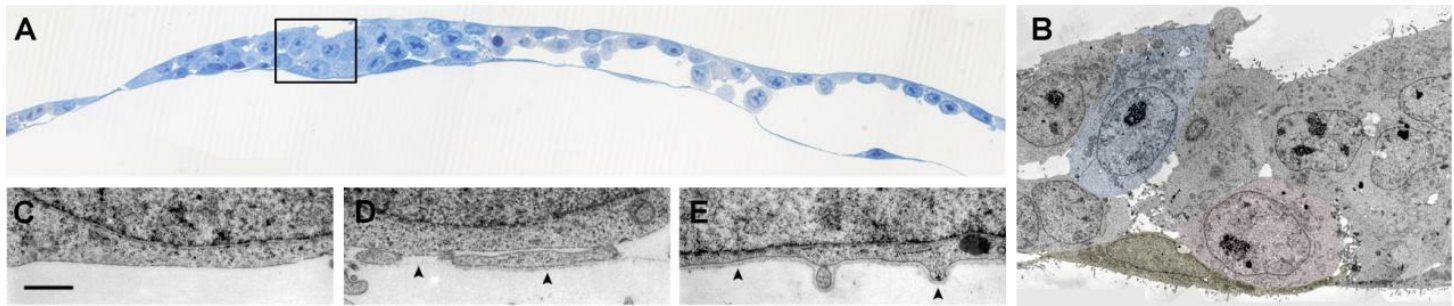

Ectopic epithelio-mesenchymal transition is revealed laterally to the midline while lack of basement membrane is found in the entire posterior gastrula extension (PGE) area of ROCK-inhibited embryos. A, Transversal semithin section from the PGE showing one half of the embryo (midline is near the left edge). Box indicates the area shown in B. B-E, Ultrathin sections showing epithelio-mesenchymal hinge with bottle cells (blue shading) on the left of the hinge point (center of panel B) and mesodermal cells (pink shading) on both sides of the hinge point, epiblast cell in the PGE area (posterior midline) lacking an underlying basement membrane $(\mathbf{C})$, epiblast cell in non-PGE area (anterior midline) with thin basement membrane (D, arrowheads), and (extraembryonic) trophoblast cell with regular basement membrane (E, arrowheads). Yellow shading in (B) marks hypoblast. Scale bar: A $10 \mu \mathrm{m}$, B $2 \mu \mathrm{m}$, C-E $1 \mu \mathrm{m}$. 


\section{Figure S4}
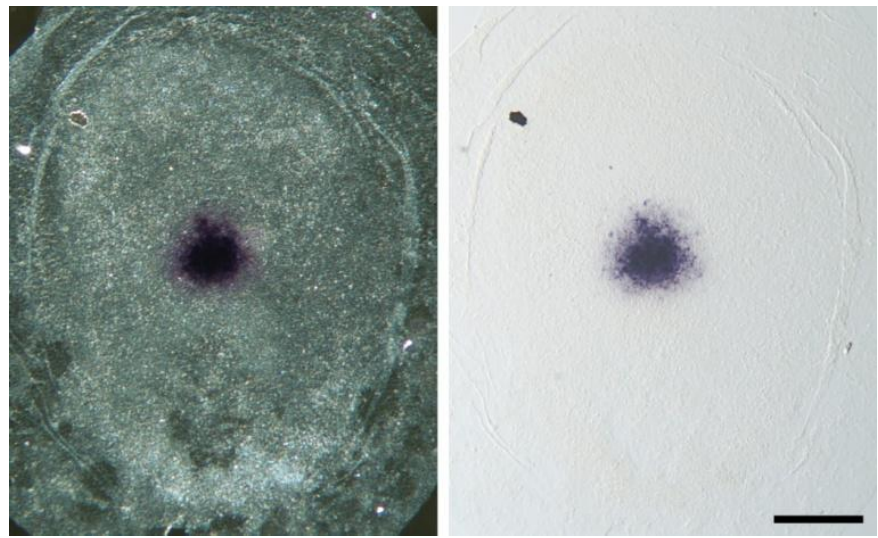

Dorsal organizer retains its regular molecular identity in ROCK-inhibited embryos. A, B, Dorsal views of expressing Chordin embryo treated with $40 \mu \mathrm{M}$ ROCK-inhibitor shown in dark-field (A) and bright-field (B) illumination. A, B $100 \mu \mathrm{m}$. 


\section{Figure S5}

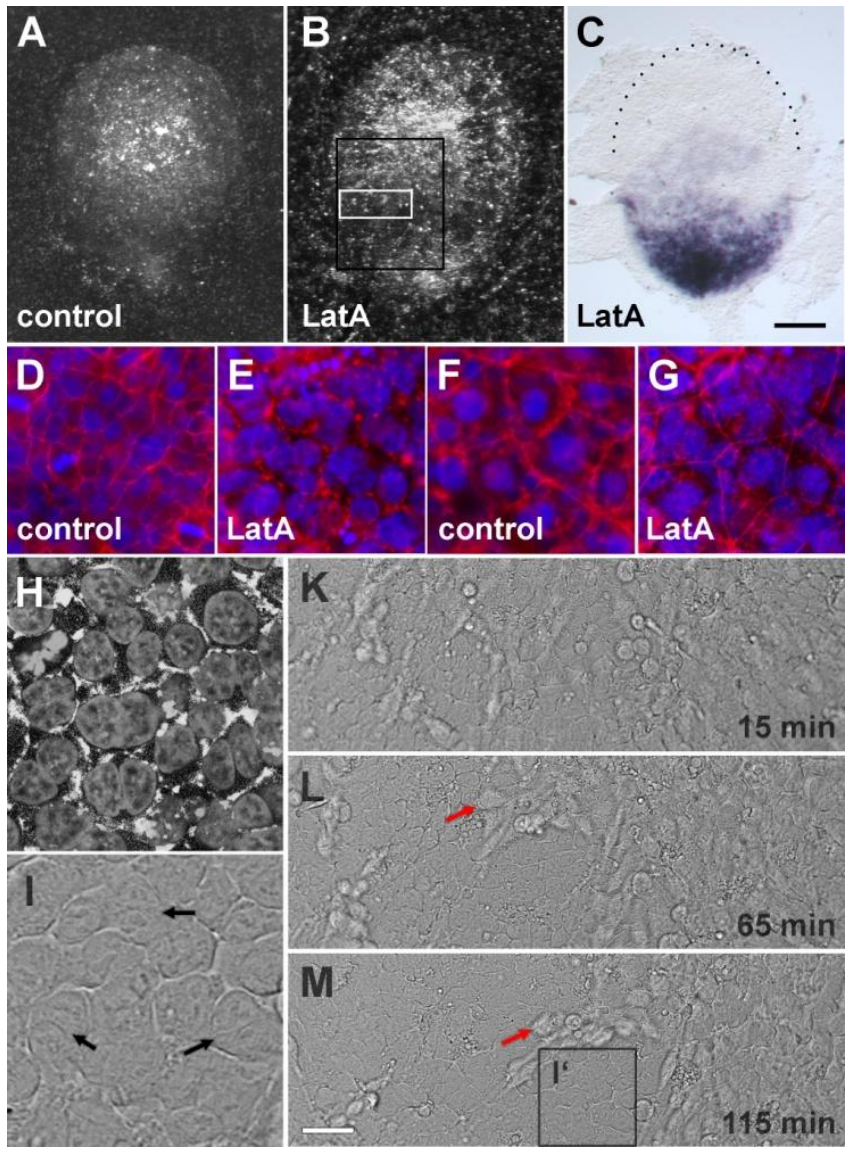

Latrunculin A (LatA) severely affects actin cytoskeleton and causes failure of cell movements and cell divisions in the whole embryonic disc. A-C, Dorsal views of control (A) and LatA-treated (B, C) embryos. D-H Phalloidin-TRITC/DAPI staining in control (D, F) and LatA-treated embryo (E, G). I-M DIC images of the central epiblast (I, same area as in $\mathbf{H}$ ) and of selected frames (cf. white box in B) of a 120 min movie (Suppl. Inform. Video 4). LatA-treated embryos have an abnormal hypoblast accumulation in the centre of the embryo (B) and a widened Brachyury expression domain $(\mathbf{C})$; actin cytoskeleton of epiblast cells is severely disturbed in the whole embryo (cf. D and E), whereas in hypoblast cells actin cytoskeleton is less severely disturbed (cf. F and $\mathbf{G}$ ). (H-I) Cytokinesis of epiblast cell divisions frequently fail ( $\mathbf{H}, \mathbf{I}$; cf. box $\mathbf{I}$ ' in $\mathbf{M})$. Black arrows in $\mathbf{I}$ point to unseparated daughter cells. Red arrows in $\mathbf{L}$ and $\mathbf{M}$ mark the same hypoblast cell at different time points of the movie. Black box in B marks area selected for movie (Video 4). Scale bar: A-C 250 $\mu \mathrm{m}, \mathbf{D}-\mathbf{I} 10 \mu \mathrm{m}, \mathbf{K}-\mathbf{M} 50 \mu \mathrm{m}$. 


\section{Tables S1-S2:}

Table S1. Dose-dependent primitive streak (PS) development

\begin{tabular}{ccccc}
\hline \multicolumn{6}{c}{ № embryos treated with ROCK inhibitor (\% total) } \\
\hline \hline & $\begin{array}{c}\text { control } \\
(n=8)\end{array}$ & $\begin{array}{c}10-30 \mu \mathrm{mol} \\
(n=8)\end{array}$ & $\begin{array}{c}40 \mu \mathrm{mol} \\
(\mathrm{n}=87)\end{array}$ & $\begin{array}{c}50-100 \mu \mathrm{mol} \\
(\mathrm{n}=6)\end{array}$ \\
\hline \hline Normal PS & $8 / 8(100)$ & $0 / 8(0)$ & $6 / 87(18)$ & $0 / 6(0)$ \\
\hline \hline Widened PS & $0 / 8(0)$ & $8 / 8(100)$ & $50 / 87(63)$ & $4 / 6(0)$ \\
\hline \hline No development & $0 / 8(0)$ & $0 / 8(0)$ & $9 / 87(19)$ & $2 / 6(33)$ \\
\hline \hline
\end{tabular}


Table S2. Forms of gastrulation centers and developmental stage at start of culture № embryos treated with $40 \mu \mathrm{mol}$ ROCK inhibitor (\% total)

\begin{tabular}{cccccc}
\hline \hline & $\begin{array}{c}\text { Stage 1 } \\
(n=4)\end{array}$ & $\begin{array}{c}\text { Early stage 2 } \\
(n=17)\end{array}$ & $\begin{array}{c}\text { Late stage 2 } \\
(n=44)\end{array}$ & $\begin{array}{c}\text { Early stage 3 } \\
(n=14)\end{array}$ & $\begin{array}{c}\text { Late stage 3 } \\
(n=8)\end{array}$ \\
\hline \hline Normal PS & $0 / 4(0)$ & $1 / 17(6)$ & $3 / 44(7)$ & $1 / 14(7)$ & $3 / 8(38)$ \\
\hline \hline WGC grade 1 & $0 / 4(0)$ & $2 / 17(12)$ & $8 / 44(18)$ & $3 / 14(21)$ & $3 / 8(38)$ \\
\hline \hline WGC grade 2 & $1 / 4(25)$ & $3 / 17(18)$ & $13 / 44(30)$ & $4 / 14(29)$ & $2 / 8(25)$ \\
\hline \hline WGC grade 3 & $0 / 4(0)$ & $2 / 17(12)$ & $15 / 44(34)$ & $5 / 14(36)$ & $0 / 8(0)$ \\
\hline \hline No development & $3 / 4(75)$ & $9 / 17(53)$ & $5 / 44(11)$ & $1 / 14(7)$ & $0 / 8(0)$ \\
\hline \hline
\end{tabular}

PS - primitive streak

WGC - widened gastrulation center 


\section{Movies S1-S4:}

Movie S1: DIC time-lapse movie (first $190 \mathrm{~min}$ ) of the control embryonic disc shown in Fig. 1A-E (cf. box in A), starting immediately prior to gastrulation and using a 10x objective. Anterior is to the left; asterisks mark the anterior and posterior borders of the embryonic disc. Red tracks highlight individual cell movements in the posterior half of the embryonic disc. Note the primitive streak starting to form in the right half of the area shown. For details see legend of Fig. 1.

Movie S2: Same movie as in Movie S1 but showing the complete time-lapse sequence (240 $\min )$.

Movie S3: DIC time-lapse movie (190 min) of the ROCK-inhibited embryonic disc shown in Fig. 1F-J (cf. box in F), starting immediately prior to gastrulation and using a 10x objective. Anterior is to the left; asterisks mark the anterior and posterior borders of the embryonic disc. Red tracks highlight centrifugal cell movements (instead of L- and Uturns) following straight paths towards the border of the embryonic disc. For details see legend of Fig. 1.

Movie S4: DIC time-lapse movie (120 min) of the LatA-treated embryonic disc shown in fig. S4 (cf. black box in B) starting immediately prior to gastrulation and using a 20x objective. Anterior is to the left. Epiblast cells present small oscillating movements, whereas hypoblast cells detach from the embryonic border, move towards the centre of the embryonic disc (cf. red arrows in fig. S4L and M) and build an artificial star-like structure in the centre of the embryonic disc. For details see legend of Fig. S4. 


\section{Curriculum Vitae}

\section{Personal Details}

Name

Date and Place of Birth

Nationality

EDUCATION

March 2009 - present

Oct. 2006 - Sept. 2008

Oct. 2007- March 2008

Oct. 2002 - Sept. 2006

Professional EXPerience

March 2009 - present

Dec. 2006 - Sept. 2007

\section{TEACHING EXPERIENCE}

March 2009 - present

Dec. 2006 - Sept. 2007
Viktoria Stankova, née Halacheva

May $9^{\text {th }}, 1983$ in Pazardzhik, Bulgaria

Bulgarian

\section{Doctoral Candidate}

University of Göttingen, Germany

Center of Anatomy, Department of Anatomy and Embryology Initial Grant: DFG, Vi 151/8-1

Program: Biology, Georg-August University School of Science (GAUSS)

\section{Master of Science in Molecular Biology}

Sofia University "St. Kliment Ohridski”, Sofia, Bulgaria

Specialization: Microbiology

\section{Foreign Exchange Master's Student}

University of Göttingen, Germany

Institute of Microbiology and Genetics

Research Scholarship: SOCRATES/ERASMUS EU Program

\section{Bachelor of Science in Molecular Biology}

Sofia University "St. Kliment Ohridski”, Sofia, Bulgaria

\section{Research Associate}

University of Göttingen, Germany

Center of Anatomy, Department of Anatomy and Embryology

\section{Research \& Laboratory Assistant}

University Hospital "Queen Giovanna", Sofia, Bulgaria

Microbiology and Virology Laboratory

\section{Teaching Associate}

University of Göttingen, Germany

Center of Anatomy, Department of Anatomy and Embryology

Subjects (for Human Medicine, Dentistry, Molecular Medicine):

- Current Issues of Embryological Research (Option)

- General Histology

- Microscopic Anatomy of the Organs

- Introduction to Clinical Medicine

Teaching Assistant

University Hospital "Queen Giovanna“, Sofia, Bulgaria

Microbiology and Virology Laboratory 
Conference

Presentations

March 2013

March 2013

May 2011

March 2011

Sept. 2010

Sept. 2010

March 2010

Publications

December 2013

June 2011
Poster Presentation at the $108^{\text {th }}$ Annual Meeting of the German Anatomical Society, Magdeburg, Germany

Poster Presentation at the International Joint Meeting of the German Society for Cell Biology (DGZ) and the German Society for Developmental Biology (GfE), Heidelberg, Germany

Oral Presentation at the European Molecular Biology Organization (EMBO) Workshop, Leuven, Belgium

Oral Presentation at the Joint Meeting of the German and Japanese Societies of Developmental Biologists, Dresden, Germany

Oral Presentation at the $27^{\text {th }}$ Annual Workshop of the German Anatomical Society, Würzburg, Germany

Poster Presentation at the $8^{\text {th }}$ German Society for Developmental Biology (GfE) Summer School "Common Mechanisms of Development and Regeneration”, Günzburg, Germany Poster Presentation at the $105^{\text {th }}$ Annual Meeting of the German Anatomical Society, Hamburg, Germany

Viktoria Stankova, Nikoloz Tsikolia, Christoph Viebahn, "Tracing ancestral gastrulation through modified cellular movements in the mammalian embryo" (to be submitted)

Viktoriya Halacheva, Mathias Fuchs, Jürgen Dönitz, Tobias Reupke, Bernd Püschel, Christoph Viebahn, Dev Dyn, "Planar cell movements and oriented cell division during early primitive streak formation in the mammalian embryo" 


\title{
Promovierenden-Erklärung der Georg-August-Universität Göttingen
}

\author{
Name: Stankova, Viktoria \\ Anschrift: Valentinsbreite 5, 37077 Göttingen
}

Ich beabsichtige, eine Dissertation zum Thema "Planar cell movements and axial patterning during early gastrulation of the rabbit embryo" an der Georg-August-Universität Göttingen anzufertigen. Dabei werde ich von Herrn Prof. Dr. Viebahn betreut.

Ich gebe folgende Erklärung ab:

1. Die Gelegenheit zum vorliegenden Promotionsvorhaben ist mir nicht kommerziell vermittelt worden. Insbesondere habe ich keine Organisation eingeschaltet, die gegen Entgelt Betreuerinnen und Betreuer für die Anfertigung von Dissertationen sucht oder die mir obliegenden Pflichten hinsichtlich der Prüfungsleistungen für mich ganz oder teilweise erledigt.

2. Hilfe Dritter wurde bis jetzt und wird auch künftig nur in wissenschaftlich vertretbarem und prüfungsrechtlich zulässigem Ausmaß in Anspruch genommen. Insbesondere werden alle Teile der Dissertation selbst angefertigt; unzulässige fremde Hilfe habe ich dazu weder unentgeltlich noch entgeltlich entgegengenommen und werde dies auch zukünftig so halten.

3. Die Richtlinien zur Sicherung der guten wissenschaftlichen Praxis an der Universität Göttingen werden von mir beachtet.

4. Eine entsprechende Promotion wurde an keiner anderen Hochschule im In- oder Ausland beantragt; die eingereichte Dissertation oder Teile von ihr wurden nicht für ein anderes Promotionsvorhaben verwendet.

Mir ist bekannt, dass unrichtige Angaben die Zulassung zur Promotion ausschließen bzw. später zum Verfahrensabbruch oder zur Rücknahme des erlangten Grades führen.

Göttingen, den 20.12.2013

(Unterschrift) 


\section{Danksagung}

Während meiner Doktorarbeit wurde ich von vielen Leuten begleitet und unterstützt. Im Folgenden möchte ich einige besonders erwähnen:

Mein ganz besonderer Dank gilt meinem Doktorvater, Prof. Dr. Christoph Viebahn, der mir die Möglichkeit gegeben hat, an diesem interessanten und einzigartigen Thema zu forschen. Er ist ein außergewöhnlich freundlicher und hilfsbereiter Mensch, der mich immer unterstützt und ermutigt hat. Von Professor Viebahn konnte ich sehr viel lernen, nicht nur in den Fachgebieten der Entwicklungsbiologie und Histologie, sondern auch wie man wissenschaftlich arbeitet und schreibt und dass man in der Forschung oft viel Geduld und Beharrlichkeit braucht. Weiterhin hat er mir während meiner Arbeit auch die Möglichkeit gegeben, viele Fachkonferenzen $\mathrm{zu}$ besuchen und dort meine Ergebnisse zu präsentieren.

Ich bedanke mich auch bei meinen Betreuern und Referenten, Prof. Dr. Ernst Wimmer und Prof. Dr. Thomas Pieler, die sich bereit erklärt haben, diese Aufgabe zu übernehmen.

Zu Dank verpflichtet bin ich auch Prof. Dr. Botho Bowien, der leider nicht mehr unter uns weilt. Ihm habe ich meinen ersten Forschungsaufenthalt in Deutschland während meiner Masterarbeit zu verdanken. Ich danke auch meinen Professoren in Bulgarien, die mich immer motiviert haben.

Besonders herzlich bedanke ich mich natürlich auch bei meinen lieben Kolleginnen und Kollegen, die mich die ganze Zeit begleitet und immer für eine besonders angenehme Arbeitsatmosphäre gesorgt haben. Allen Wissenschaftlern danke ich für die konstruktive Kritik und für die fruchtbaren Diskussionen, die meine Arbeit positiv beeinflusst haben. Von Anfang an wurde ich von Dr. Bernd Püschel und Dr. Peter Schwarz in der Arbeitsgruppe sehr herzlich aufgenommen. Bei Dr. Püschel bedanke ich mich auch für die Einführung in neue Labortechniken und in die Arbeit mit der konfokalen Mikroskopie. PD Dr. Jörg Männer danke ich vor allem für die wertvollen und konstruktiven Ideen während der Seminare. Dr. Nikoloz Tsikolia danke ich für die besonders hilfreichen Diskussionen und für die gute Zusammenarbeit. Den beiden letztgenannten Kollegen danke ich auch für die, nicht nur wissenschaftlichen, außergewöhnlichen Theorien und Erzählungen, die immer zur guten Laune und Inspiration der gesamten Arbeitsgruppe beigetragen haben. 
Irmgard Weiß, Kirsten Falk-Stietenroth, Heike Faust und Hannes Sydow danke ich ganz herzlich für die perfekte technische Unterstützung im Labor und für die stete Hilfsbereitschaft. Hannes Sydow danke ich zudem nicht nur für die besonders wertvollen Photoshop-Lektionen, sondern auch für die moralische Unterstützung und für die Aufmunterung. Heike Altmann danke ich für die Lösung vieler administrativer Probleme, für ihre Freundlichkeit und ihre Hilfsbereitschaft. Waad Hassan, Silke Schröder und allen anderen Mitarbeitern im Labor danke ich ebenfalls für die sehr freundschaftliche Atmosphäre und für die gute Zusammenarbeit.

Ich danke natürlich allen meinen Freunden, ganz besonders meinen Trauzeugen Alex und Olenka, für ihre Unterstützung während der ganzen Doktorarbeit.

Mein ganz spezieller Dank gilt meinen Eltern, meiner Schwester und ihrem Mann, meiner Tante und meinen Großeltern die mich immer unterstützt haben und hinter mir standen, trotz der großen Entfernung, die uns trennte. Ich danke auch der gesamten Familie Stankov für die ständige Hilfsbereitschaft und für die guten Ratschläge, ganz besonders meinem lieben Mann Anguel für seine uneingeschränkte Unterstützung in Allem was ich mache, dass er Freude und Schwierigkeiten mit mir geteilt hat und immer zu mir steht. Meiner Familie und diesen lieben Menschen, die mir ganz nahe stehen, sei daher diese Arbeit gewidmet: Обичам ви! 